\title{
Green Synthesis of Nanomaterials \\ - A Scientometric Assessment
}

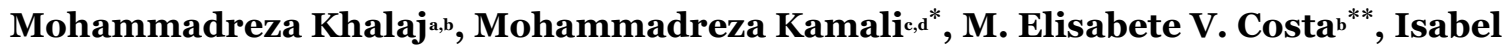 Capela ${ }^{a}$}

a Department of Environment and Planning, Center for Environmental and Marine Studies, CESAM, University of Aveiro, 3810-193 Aveiro, Portugal

b Department of Materials and Ceramics Engineering, Aveiro Institute of Materials, CICECO, University of Aveiro, 3810-193 Aveiro, Portugal

${ }^{\mathrm{c}}$ Center for Environmental and Marine Studies, CESAM, University of Aveiro, 3810-193 Aveiro, Portugal

d KU Leuven, Department of Chemical Engineering, Process and Environmental Technology Lab, J. De Nayerlaan 5, 2860, Sint-Katelijne-Waver, Belgium

\section{Abstract}

The green synthesis of engineered nanomaterials (NMs) has deserved an enormous academic interest and huge financial investments during the last decades. However, this prominent position has not been followed by the rapid commercialization of NMs for real applications thus rendering their practical usefulness very doubtful and the appropriateness of novel investments in the field highly questionable. The present manuscript presents the first scientometric study on the green synthesis of NMs aiming to survey the scientific progress in this particular field and identify its main gaps while providing applicable suggestions to facilitate the knowledge transfer from laboratories to real full scale production and applications. The research on green synthesis of nanomaterials published in Web of Science during the period 1991 - 2019 is here carefully analyzed. 9 scientometric indicators are employed to interpret the results retrieved from the 8761 documents collected. It is found that 107 countries and nearly 22400 authors have contributed to this subject, hence highlighting the relevance of this topic. The keywords spectrum is dominated by the term "nanoparticle" which full adoption takes place at the beginning of the 21st century. Some few years later a batch of words like "silver nanoparticle", "gold nanoparticle" and "nanocomposite" reaches a significant impact reflecting the emergence of commercial applications for these nanomaterials. It is only in 2009 that the keyword "green synthesis" gains strength, followed then by "biosynthesis" in 2010, making it evident a trend towards environmentally friendly reagents. The number of publications on green synthesis of nanomaterials displays now a sigmoidal like growth pattern which points actually to a decrease of new arrivals, thus suggesting a possible forthcoming decline in this field. However, the analysis carried out in the present work allows identifying various gaps related to sustainability which, if

* Corresponding authors: Mohammadreza.kamali@kuleuven.be

** Corresponding authors: Elisabete.costa@ua.pt 
appropriately addressed, may contribute to a resurgence of the research on nanomaterials synthesis while fostering more frugal approaches on material synthesis tendencies.

37 Keywords: Green Synthesis, Scientometric Study, Sustainable Synthesis, Nanomaterials. 1. Introduction

Among the green strategies recently reported for the synthesis of nanomaterials (NMs), different approaches are identified, which normally include the use of green starting raw materials such as natural polymers like chitosan [1]-[3] or plants extracts [4]-[6], or the so-called green synthesis routes such as ultrasonic irradiation [7]-[9] and microwave-assisted methods [10], [11], or a combination of methods [12], [13]. The adoption of green production routes may bring several advantages over conventional methods. For instance, conventional methods generally rely on expensive chemical reagents, tending to generate solid or liquid wastes which imply extra investments for disposing and treatment purposes [14]-[17]. Such drawbacks have raised some debate on the efficiency of the methods commonly utilized for producing NMs as economic considerations are also of high importance when selecting an appropriate synthesis method. In this regard, besides the specifications required for full efficiency such as relatively short reaction times, low temperature, environmental friendly synthesis media, other criteria associated to sustainability including technical-environmental (like low risk for operators and society), social (public acceptability and contribution for job creation) and economic considerations (initial investment, costs of raw materials and manufacturing) have to be taken into account as well [15], [18]). However, studies on nanomaterials synthesis meeting all these criteria are scarce or inexistent. Therefore, green synthesis routes, with better environmental, economic and technical feasibility than conventional methods, are now timely needed.

The profile of the publication rate in the field of NMs green synthesis evidences a trend for saturation although a corresponding widespread use of NMs is not found as could be expected. This gap may suggest a deficit on knowledge transfer from academic sectors to industry and society which detrimental effects should not be underestimated. It is commonly known that the application of research results produces a feedback amplification effect on the research dynamics itself, fostering further developments hence feeding a vicious circle correlation between both[19]. Conversely a low rate of knowledge transfer from lab-scale to real-scale applications, with a small fraction of lab-scale technologies being commercialized, will produce negative impacts on the investments necessary to the progress of the research thus slowing down novel scientific achievements [20]. Therefore, it is critically important to address the missing conditions that could render the actual research results on the field of NMs green synthesis fully useful and applicable for industry and the community in general. Scientometrics may provide important guidelines for that purpose.

Scientometric studies have been frequently used in order to study and measure the research progress and efforts from researchers, governments, research institutes, universities, faculties and scientific publishers and journals in a particular scientific subject [21]. The scientometric methodology provides a general overview of the science philosophy via the recognition of the general direction followed by the developments in a specific area during a certain period of time. This is normally performed by analyzing 
72 scientometric studies on various scientific fields has increased considerably in the more recent years, hence 73 demonstrating the importance of surveying the knowledge progress. Sustainability and sustainable 74 development [23], industrial wastewater treatment methods [24], electromagnetic studies [25], 75 regenerative medicine [26], heavy metals release from agricultural watershed to aquatic system [27], and $76 \mathrm{CO}_{2}$ underground storage [28] among others, are few examples of recent scientometric studies. By 77 overviewing the state-of-the-art evolution in a particular scientific field, its main trends and associated gaps 78 may be identified thus enabling propositions to be made for overcoming the barriers to the progress of 79 science and technology in that specific area. In what NMs green synthesis is concerned its up-scaling to 80 industrial contexts and easy commercialization is far from full attainment [29], being this a potential 81 adverse condition for the maintenance of research budgets. Scientometric studies may provide useful 82 information to elucidate this problem and point out possible solutions. However, to the best of our 83 knowledge, there are no literature reports on scientometric studies covering green synthesis methods for 84 NMs production despite the high number of publications on this field which may provide useful information 85 to promote green fabrication processes. Considering that the technologies already developed at lab-scales 86 are currently mature for transference, it seems crucial to overview the progress made in this field so as to 87 identify the barriers to the rapid commercialization of those technologies that have proved their efficiency 88 for real applications. Therefore, the present study aims at a scientometric analysis of the green synthesis of 89 NMs in order to assess the efforts already made in the area of knowledge transfer while addressing its 90 hindering factors. For that purpose, sustainability criteria (i.e. technical, environmental, social and 91 economic ones) are here used to frame the discussion of scientometric data aiming to promote the real and 92 sustainable application of engineered nanomaterials.

\section{Methodology}

In this study, the Web of Science (WoS) Core Collection database was used to collect data in the span 96 of time 1991-2019, considering all the citations indexed in Science Citation Index Expanded (SCI97 EXPANDED). A specific combination of keywords based on an advanced search in the WoS database (see

98 supplementary information), was utilized. In order to identify the appropriate combination of keywords 99 which could be representative of the relevant literature, a search based on a preliminary list of keywords 100 corresponding to the topic of the present study (green, synthesis, and nanomaterials) was performed 101 allowing to extract a primary list of papers published in this area. This list was then used to identify and 102 refine the keywords with higher relevance, and then their combination to be used in the final WoS search. 103 The WoS outputs were saved as "Marked List" and then they were saved as "text" format in order to be 104 further used in CiteSpace software (version 5·5.R2) according to the manual provided by CiteSpace [30]105 [32]. A schematic of the process implemented in this study is presented in Fig. 1. 
106

107

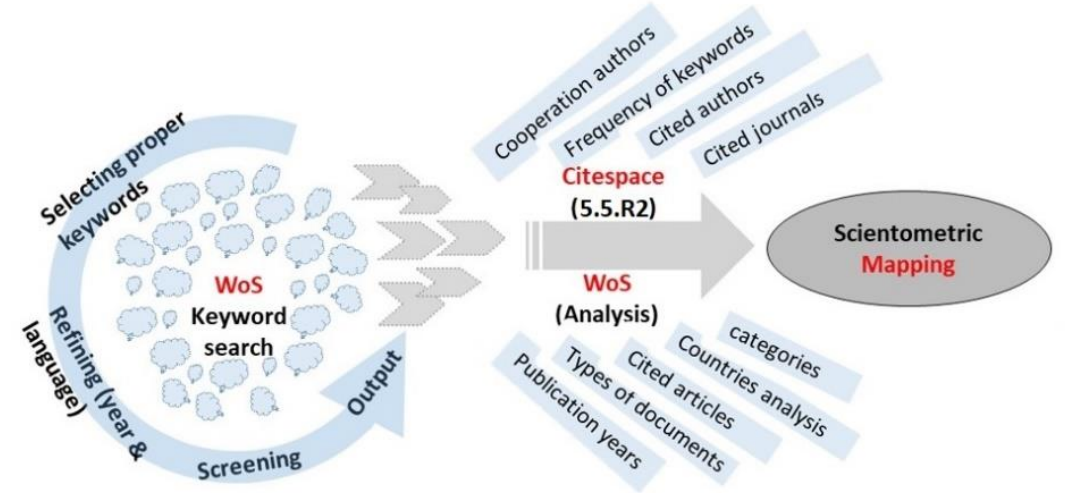

Fig. 1.

A schematic of the research design.

Nine scientometric techniques were utilized including analysis of (1) publications, (2) document types, (3) contribution of the countries, (4) authors, (5) keywords, (6) cited authors, (7) cited journals, (8) categories, and (9) cited articles. To proceed with the analysis, the parameters used in this study for the scientometric analysis are further elaborated as follows.

\subsection{Scientometric parameters}

\section{a) Betweenness Centrality (BC)}

Betweenness Centrality, introduced in 1948, is considered as one of the most critical metric parameters for the specification of every node in a network. BC qualifies the centrality of a node by indicating the extent to which it is located in the shortest line between others [33]. It is a subdivision concept of graph theory demonstrating the alternation of a node in a diagram. This parameter is represented as $\mathrm{BC}(\mathrm{k})$ when standing for the node $\mathrm{k}$. It is calculated by Eq. (1).

$$
B C(k)=\sum_{i \neq j \neq k} \frac{\Delta_{i j}(k)}{\Delta_{i j}}
$$

Where $\Delta \mathrm{ij}$ is the number of shortest links between ending nodes $\mathrm{i}$ and $\mathrm{j}$, and $\Delta \mathrm{ij}(\mathrm{k})$ represents the number of the shortest links that cross the node $\mathrm{k}$. If a node contains high $\mathrm{BC}$, it can be concluded that it is located on a significant fraction of shortest links, meaning that it contains lots of connections with other nodes. $\mathrm{BC}$ of all the nodes are values lying in the range [0,1]. When $\mathrm{BC}$ of any intermediate node is maximum, it has the value 1 ; its value will be zero whenever only one line connects two ending nodes and at the same time $\mathrm{BC}$ of other nodes is minimum. Likewise, if there are $\mathrm{n}$ lines connecting two ending points, those two ending points will provide the value of $\mathrm{BC} / \mathrm{n}$ for all the intermediate nodes [34].

\section{b) Citation Burst (CB)}

According to Chen (2014) the "citation burst" is an indicator that identifies the most active area (including certain references, authors, etc.) in a specific scientific field according to Kleinberg (2003). Simply, if there are $\mathrm{n}$ batches of documents, and the $\mathrm{t}^{\text {th }}$ batch contains $\mathrm{r}_{t}$ relevant documents out of a total of $d_{t}$, then citation burst (CB) is defined as: 


$$
C B\left(i, r_{t}, d_{t}\right)=-\ln \left[\left(\begin{array}{l}
n \\
k
\end{array}\right) P_{i}^{r_{t}}\left(1-P_{i}\right)^{d_{t}-r_{t}}\right]
$$

since this is the negative logarithm of the probability that $r_{t}$ relevant documents would be generated using a binomial distribution with probability $\mathrm{p}_{\mathrm{i}}$.

\section{c) Sigma}

Sigma is an indicator that combines the strength of the structural and temporal properties of a node in scientometric graphs [32]. In other words, it combines betweenness centrality and citation burst to measure the scientific novelty of a reference. Sigma is calculated according to Eq. 3 [36];

$$
\text { Sigma }=(\mathrm{BC}+1)^{\mathrm{CB}}
$$

\section{d) Citation Counts (CC)}

Citation count indicator measures the number of citations that a certain publication has received during a certain period of time. Three main databases can be utilized to provide the CCs including WoS, Scopus, and Google Scholar. CC can be defined for authors, for an individual article, and for a particular journal [37], [38]. A high CC indicates that an author, an article, or a journal has deserved high attention from the scientific community [39].

e) Citation Frequency (CF)

Citation frequency is defined as the total number of citations received by a certain publication during a certain period of time divided by the citation period (years) [40].

\section{f) Clustering}

When the group under analysis is divided into some sub-categories with certain similarities, this process is called "clustering". In other words, each cluster contains data possessing characteristics that are similar and at the same time, these characteristics may differ among clusters. The strength of a cluster is rated as "\#x" where $x$ may assume integer values $(0,1,2, \ldots$ etc.), depending on the similarity of the cluster data: data very similar will define a very strong cluster, being the strongest cluster identified as "cluster\#o"; clusters \#1, \#2, ... etc are considered to display a decreasing strength as compared to cluster\#O [41].

\section{Results}

A combination of keywords including synthesis, fabrication, preparation, green, sustainable, ultrasonic, microwave, sonochemistry, nano, and nanomaterial was used in this scientometric study. The keywords search was also denoted with a “*” (see the supplementary information) refined with the English language and a time period ranging from 1991 to 2019 resulted in a total of 8761 WoS records. The analysis of the main parameters including publication history (section 3.1), document types (section 3.2), countries contribution (section 3.3), authors (section 3.4), keywords (section 3.5), cited authors (section 3.6), cited journals (section 3.7), categories (section 3.8), and cited articles (section 3.9 regarding the extracted WoS records will be next presented.

\subsection{Publication history}


Fig. 2 represents the time evolution of the number of published documents on NMs green synthesis 169 (including scientific articles, review papers, proceeding papers, meeting abstracts, and other types of 170 documents) during the studied time period (1991-2019). According to this figure, the largest record belongs 171 to the year 2019 with a total number of 1139 documents published, whereas only one document was 172 published in 1991, thus demonstrating that scientific efforts in this field have started to grow in the 1990s. 173 Also, the cumulative number of published documents follows a sigmoidal like pattern indicating that the 174 growth rate of the number of publications in this field is tending to a slight slowdown.

\section{5}

176

177

179

180

181

182

183

184

185

186

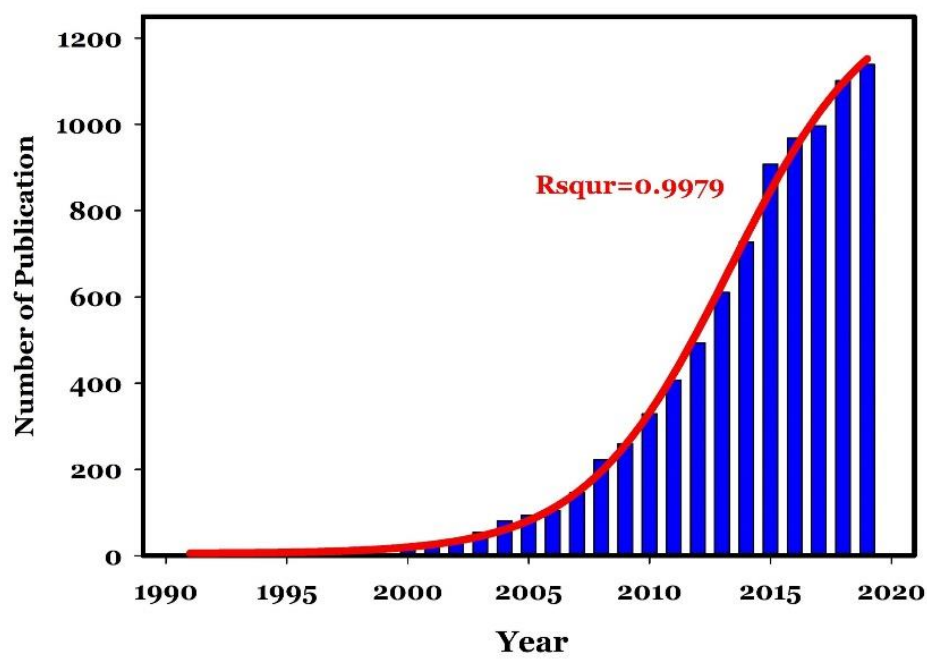

Fig. 2

Distribution of the published documents during 1991-2019 and sigmodial pattern of the cumulative number of publications over the studied period of time.

\subsection{Document types}

The contributions (in \%) of the various documents published in the field under analysis, including proceeding papers (PP), meeting abstracts (MA), articles (A), reviews (R) and other types of documents (O) such as corrections, letters, editorial material, retracted publications, news items, retractions, data papers and notes based on the results of searching the subject "green synthesis of nanomaterials" in WoS database, are presented in figure 3. As observed, articles share $87.60 \%$ of the documents published in this field while review articles and other document types represent a percentage of only $1.54 \%$ and $1.41 \%$ respectively. Proceeding papers (6.76\%) and meeting abstracts (2.69\%) share almost $10 \%$ of the published documents. 


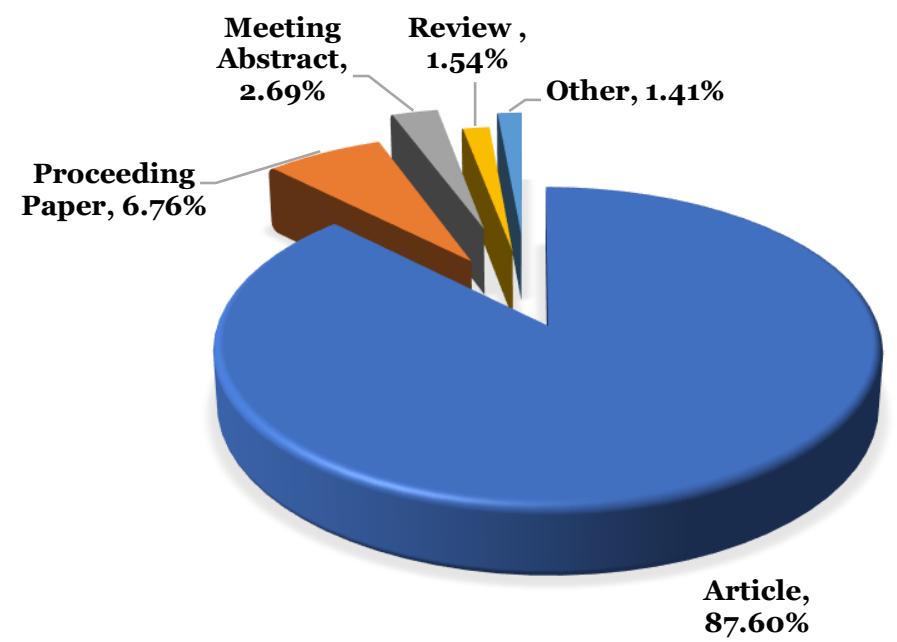

Shares of the various document types published on the green synthesis of NMs since 1990 . Articles with a share of $87.60 \%$ which are 190 by far the documents with the highest share suggest that scientists in this field prefer to publish their works as indexed papers over 191 other kind of scientific documents such as conference papers or meeting abstracts.

\section{$192 \quad 3 \cdot 3$ Contribution of the countries}

193 Fig. 4. and Table 1. illustrate the outputs of WoS regarding the contribution of various countries for 194 generating scientific publications on green synthesis of NMs. According to these results, 107 countries have 195 so far contributed to the publication of various types of documents in this field. The republic of China with 1962151 scientific documents shares the highest number of publications among the contributing countries. 197 India with 1973 scientific documents and Iran with 1644 scientific documents have received the second and 198 third positions, respectively; USA, South Korea, Saudi Arabia, Japan, Malaysia, Taiwan, and Egypt with $199685,556,260,247,205,187$, and 171 documents, respectively, were ranked 4th to 10 th place.

\section{Table 1.}

201 Contributions of various countries for the production of scientific documents on green synthesis of nanomaterials.

\begin{tabular}{lll}
\hline Rating & Country & Counts \\
\hline 1 & China & 2151 \\
2 & India & 1973 \\
3 & Iran & 1644 \\
4 & USA & 685 \\
5 & South Korea & 556 \\
6 & Saudi Arabia & 260 \\
7 & Japan & 247 \\
8 & Malaysia & 205 \\
9 & Taiwan & 187 \\
10 & Egypt & 171 \\
\hline
\end{tabular}


Fig. 4.
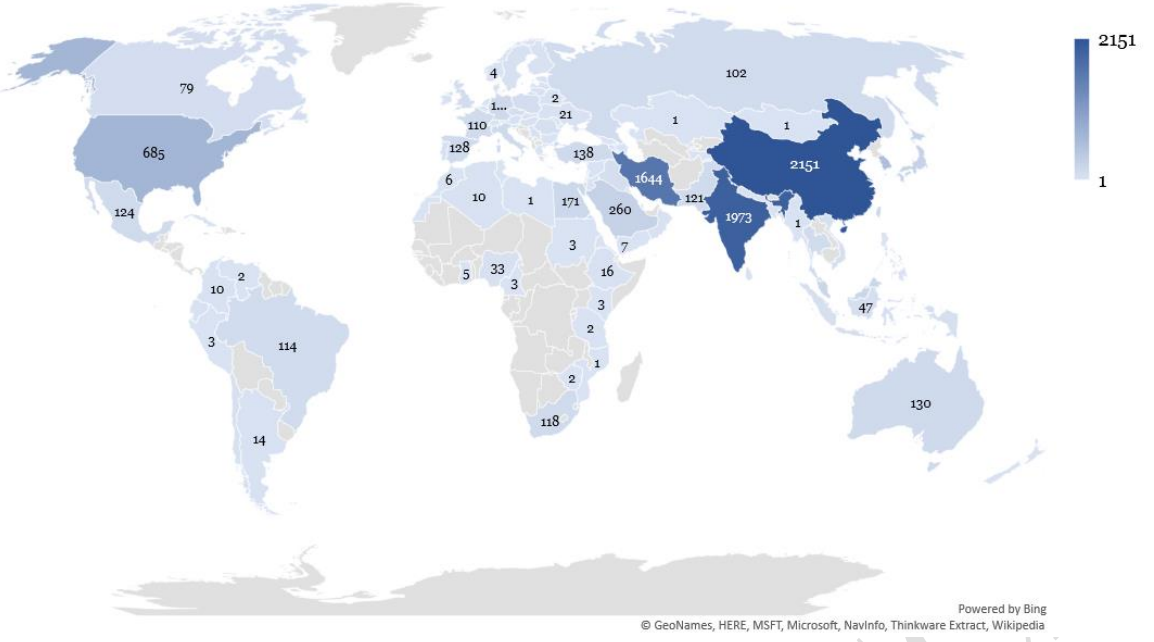

Worldwide countries contributions for the production of scientific documents on green synthesis of NMs. China, India, and Iran have the highest shares in this scientific area.

\subsection{Authors}

The results extracted from Citespace software were used for analyzing the contributions of the authors which are listed in table 2 and graphically presented in Fig. 5. A total number of 22338 authors have

212 contributed to the field of green synthesis of NMs. As observed, Salavati Niasari with 107 documents,

213 Morsali with 104 documents, and Gedanken with 55 documents published in WoS have achieved the first

214 three ranks. Collaborations among groups are also clearly identified although some isolated groups lacking

215 interconnection are noticed as well.

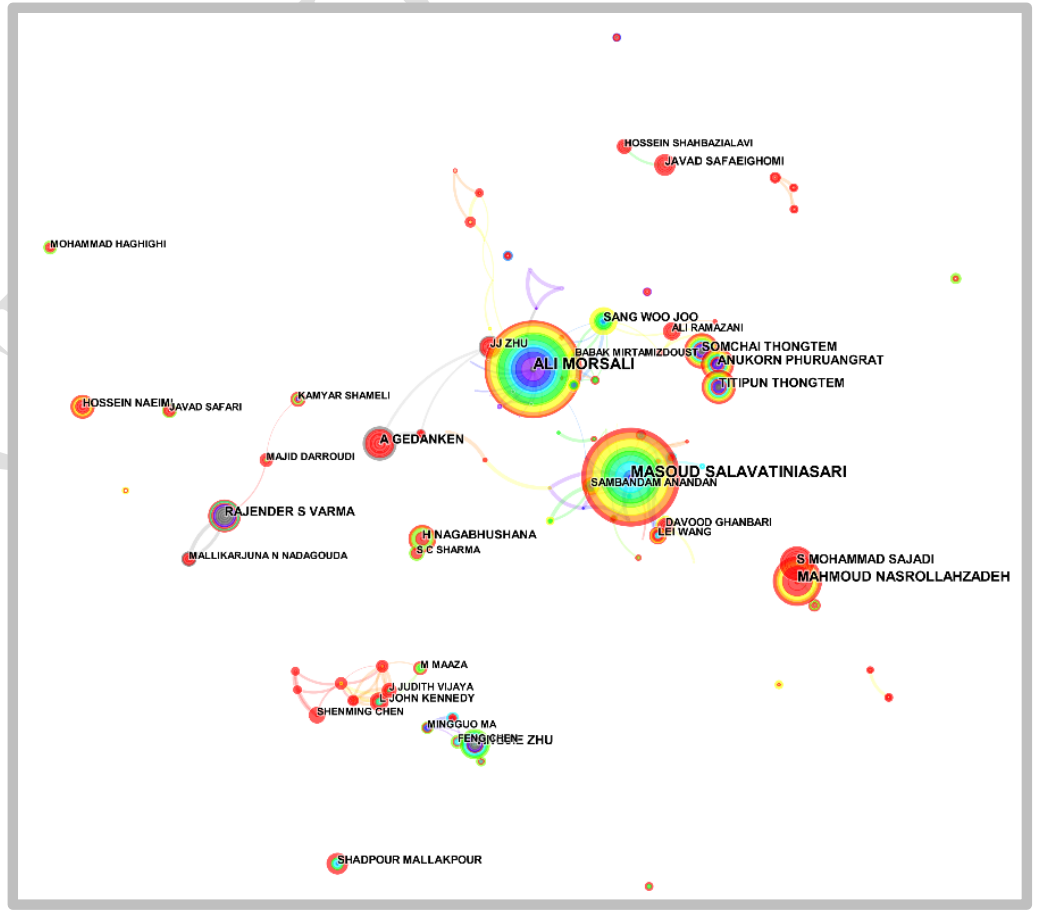

Fig. 5 . 
Graphical outcomes from CiteSpace showing the authors' contributions as a network containing both nodes and links in which each symbolic node refers to an author and each link is used to interpret the pattern of cooperation among the authors [23]. Authors like Salavati-Niasari and Morsali, stand out as having the highest contributions.

Table 2.

List of authors with relevant contributions for the production of scientific documents on green synthesis of nanomaterials. Salavati-

Niasari, and Morsali have the highest contributions among the authors.

\begin{tabular}{lll}
\hline Rating & Authors & Counts \\
\hline 1 & Salavati-Niasari M. & 107 \\
2 & Morsali A. & 104 \\
3 & Gedanken A. & 55 \\
4 & Nasrollahzadeh M. & 54 \\
5 & Varma R.S. & 52 \\
6 & Zhu Y.J. & 48 \\
7 & Zhu J.J. & 47 \\
8 & Wang Y. & 45 \\
9 & Thongtem S & 43 \\
10 & Wang J. & 43 \\
\hline
\end{tabular}

\subsection{Keywords}

Keywords analysis is considered an essential tool to characterize a scientific domain in a specific field

228 [42], [43]. The network of keywords can also reveal how they are related to each other and how they can be used for identifying the most suitable document among existing publications in a scientific area [44]. WoS

230 database covers two types of keywords including "author keywords" which are provided by the authors, and

231 "keywords plus" that are retrieved from journal indexes. In this study, both types of keywords have been

232 utilized [45]. Relying on Citespace software outputs, the keywords with the highest frequency were 233 identified as follows: nanoparticle (frequency: 2148), silver nanoparticle (frequency: 1098), and green

234 synthesis (frequency: 973). Table. 3 and Fig. 6 present the results of the keywords analysis and Fig. 7 traces 235 the keywords development during the studied period of time (1991-2019).

236 Table 3.

237 Analysis of keywords occurrence. "Nanoparticle" stands out as the keyword with the highest frequency.

\begin{tabular}{llllll}
\hline Rating & Keyword & Sigma & Centrality & Burst & Frequency \\
\hline 1 & Nanoparticle & 1 & 0.1 & & 2148 \\
2 & $\begin{array}{l}\text { Silver } \\
\text { nanoparticle }\end{array}$ & 1 & 0.03 & & 1098 \\
& $\begin{array}{l}\text { Green } \\
3\end{array}$ & & & \\
& synthesis & 1 & 0.02 & & 973 \\
4 & Nanostructure & 1 & 0.07 & & 785 \\
5 & Nanocomposite & 1 & 0.11 & & 701 \\
6 & Biosynthesis & 1 & 0 & 699 \\
7 & Gold & & & \\
& nanoparticle & 1 & 0.04 & & 657 \\
8 & Growth & 117.82 & 0.14 & 35.63 & 637 \\
9 & Nanocrystal & 1.46 & 0.04 & 8.86 & 627 \\
10 & Composite & 1 & 0.06 & & 574 \\
11 & Reduction & 1 & 0.06 & & 560 \\
12 & Particle & 18.47 & 0.11 & 29.2 & 501 \\
13 & Performance & 1 & 0 & & 474 \\
14 & Size & 1 & 0.05 & & 470 \\
15 & Catalyst & 1 & 0.08 & & 462 \\
16 & Fabrication & 1 & 0.02 & & 455 \\
17 & Optical & & & \\
& property & 1 & 0.05 & & 448 \\
& & & &
\end{tabular}




\begin{tabular}{llllll}
18 & Microwave & 1.07 & 0.02 & 3.86 & 431 \\
19 & Oxide & 1 & 0.07 & & 409 \\
20 & Nanorod & 3.11 & 0.04 & 25.89 & 407 \\
\hline
\end{tabular}

\section{Fig. 6.}

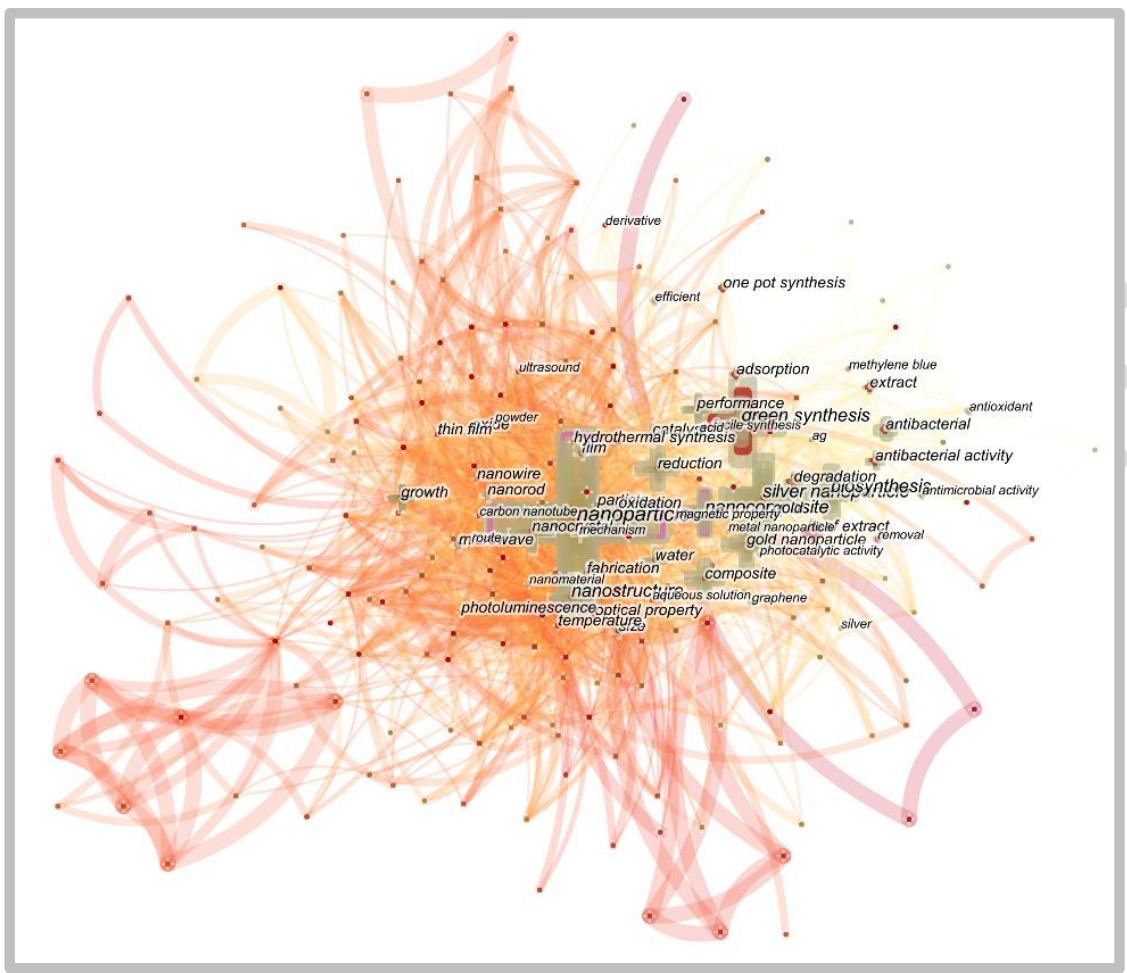

Keywords occurrence pattern. The size of nods reflects the frequency of each keyword [23]. The keywords "Nanoparticles", "Silver nanoparticle", and "Green synthesis" display the highest frequencies.

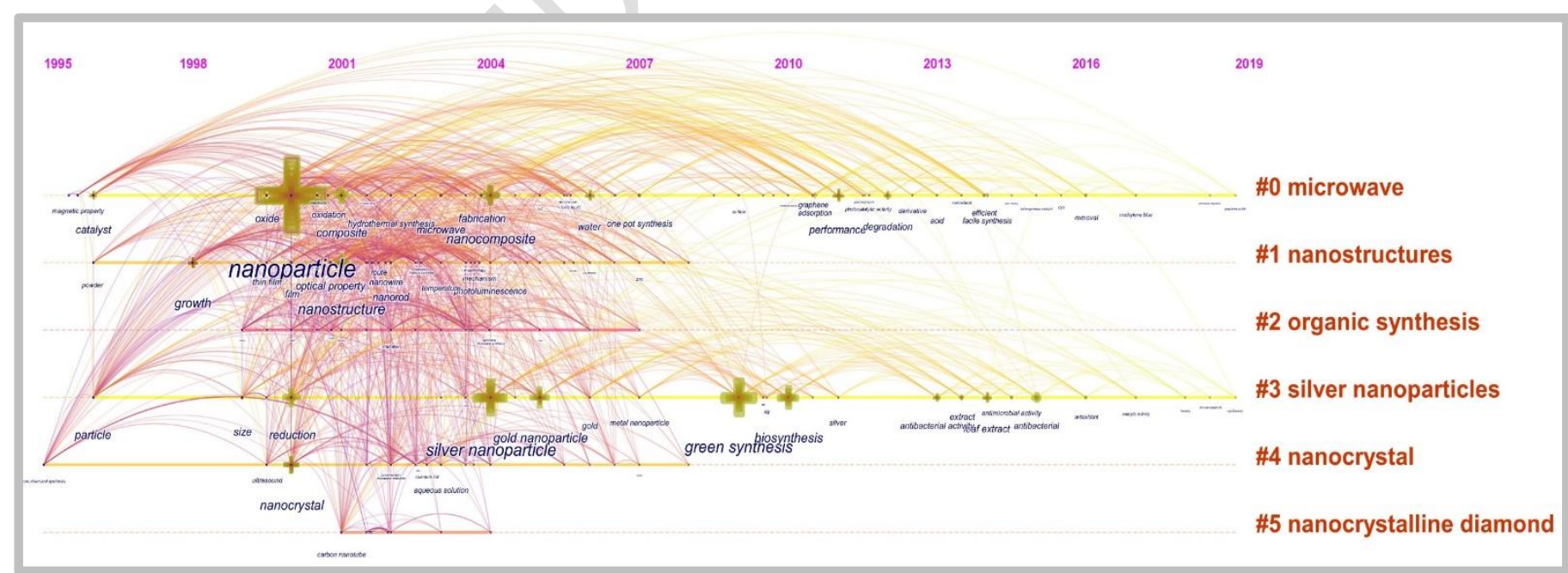

Evolution trend of keywords during the studied time period (1991-2019). The size of nods indicates the frequency of keywords occurrence in the studied documents during the mentioned period of time. The keywords "nanoparticle" in the cluster \#0, "silver nanoparticle", and "Green synthesis" in the cluster \#3 display the highest frequencies which are found in the first decade of the $21^{\text {st }}$ century.

\subsection{Cited authors}


Identifying the authors' collaboration networks in a specific scientific area allows distinguishing both 253 the experts in the field with the highest contributions and the main funding organizations [46], [47]. In 254 addition, this tool can reveal the collaborative efforts among the authors, and the author's impact on the 255 scientific area under consideration. These outcomes can be identified using variables such as citation 256 quantity, citation burst, betweenness centrality, and citation sigma. Table 4, and Figure 8 presents the 257 results achieved for cited authors' analysis using the Citespace program. According to the authors' citation 258 frequency, the top-ranked author is Suslick K.S. (frequency = 549). The second place belongs to Wang Y. 259 (frequency $=460$ ), Shankar S.S. (frequency $=441$ ), and Raveendran P. (frequency = 335) owned the next 260 positions. Furthermore, M. Nasrolazadeh (2017-2019) in cluster \#3 with burst of 58.89, S. Komarneni 261 (2003-2012) in cluster \#8 with the burst of 54.25, and S. Ahmed (2017-2019) in cluster \#3 with the burst 262 of 53.95 have been identified the top ranked authors in terms of citation burst strengths. Also, M. 263 Nasrolazadeh in cluster \#3, S. Komarneni in cluster \#8, and S. Ahmed in cluster \#3 the centralities were 264 measured o.oo. Finally, the top-ranked authors according to the calculated sigma values are $\mathbf{M}$. 265 Nasrolazadeh in cluster\#3, S. Komarneni in cluster \#2, and S. Ahmed in cluster \#3 with the sigma of 1.oo. 266 The largest cluster \#0 is labeled as "ionic liquid" with 80 members. The second position belongs to cluster 267 \#1 labeled as "coordination polymer" with 66 members. Finally, cluster \# 2 is located in the third position 268 labeled as "microwave-polyol method" with 51 members.

271 Citespace results regarding the analysis of cited authors. Suslick K.S. is the author with the highest citation frequency.

\begin{tabular}{lllllll}
\hline Rating & Author & Year & Sigma & BC & CB & CF \\
\hline 1 & Suslick K.S. & 1995 & 1 & 0 & 1.29 & 549 \\
2 & Wang Y. & 2000 & 1 & 0 & & 460 \\
3 & Shankar S.S. & 2009 & 1 & 0 & 14.67 & 441 \\
4 & Raveendran P. & 2006 & 1 & 0 & 1.19 & 335 \\
5 & Wang J. & 2007 & 1 & 0 & 1.37 & 303 \\
6 & Zhang Y. & 2006 & 1 & 0 & 20.02 & 302 \\
7 & Zhang J. & 2005 & 1 & 0 & 0.47 & 299 \\
8 & Wang X. & 2005 & 1 & 0 & 0.47 & 290 \\
9 & Zhang H. & 2007 & 1 & 0 & 2.07 & 290 \\
10 & Wang H. & 2002 & 1 & 0 & 1.26 & 288 \\
\hline
\end{tabular}




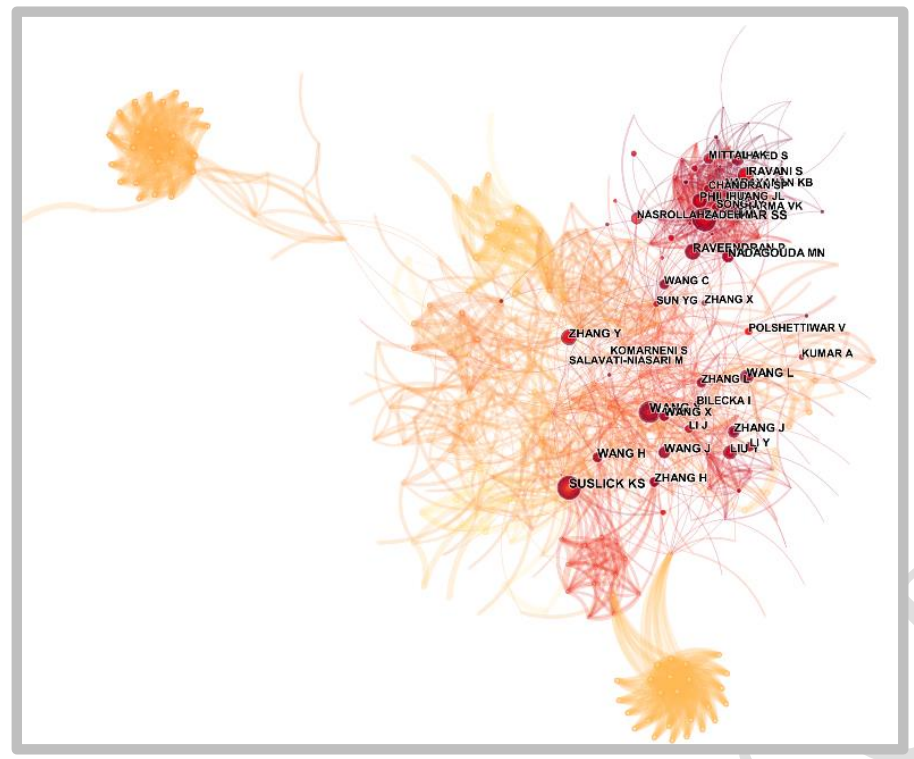

\section{Fig. 8.}

Cited authors schematic where the citation frequency for each author is shown by the node size [23]. As observed the authors "Suslick K.S.", "Wang Y.", and "Shankar S.S." have the highest citation frequency.

\section{$278 \quad 3.7$ Cited journals}

279 Table 5. and Figures 9, and 11 present the outputs of Citespace regarding the analysis of cited journals

280 based on various parameters such as the number of journal citations, citation burst, betweenness centrality, 281 and finally the citation sigma. According to the obtained results respecting journal citations, the top-ranked 282 journal is "Journal of the American Chemical Society" with a frequency of 3728 . The second rank journal is 283 "Materials Letters" with a frequency of 3048, followed by "Chemistry of Materials" in the third rank with a 284 frequency of 3016. In terms of the citation bursts strength, RSC Advances (2017-2019) in cluster \#2 with a 285 burst of 223.64, Journal of Crystal Growth (2001-2013) in cluster \#O with a burst of 167.04, and Chemical 286 Physics Letters (2000-2012) in cluster \#O with a burst of 154.96 are the top-ranked journals in the this 287 scientific field. In addition, when considering the centrality, Materials Letters in cluster \#1 with a centrality 288 of 0.13, Angewandte Chemie International Edition in cluster \#2 with a centrality of 0.13, and Advanced 289 Materials in cluster \#2 with a centrality of 0.12 are the top-ranked journals. Regarding sigma, Journal of 290 the American Ceramic Society in cluster\#1 with a sigma of 18930, RSC Advances in cluster \# 2 with a sigma 291 of 12323, and The Journal of Physical chemistry in cluster\# o with a sigma of 4092 are ranked in the top. 292 The largest cluster (\#O) is labeled as "nanocrystalline diamond film" with 35 members. Also, cluster \#1 is 293 labeled as "nanoparticles synthesis" with 33 members in second place.

294 Table 5.

295 Citespace results regarding the analysis of cited journals. Journal of the American Chemical Society has the highest citation frequency.

\begin{tabular}{lllllll}
\hline Rating & Journal & Year & Sigma & BC & CB & CF \\
\hline 1 & Journal of the American Chemical Society & 1996 & 1.06 & 0.04 & 1.38 & 3728 \\
2 & Materials Letters & 2001 & 1 & 0.13 & & 3048 \\
3 & Chemistry of Materials & 1996 & 2.26 & 0.09 & 9.76 & 3016 \\
4 & Journal of Materials Chemistry & 1999 & 1.29 & 0.05 & 5.09 & 2799 \\
5 & The Journal of Physical Chemistry C & 2008 & 1 & 0.03 & & 2771 \\
6 & Langmuir & 1997 & 1.26 & 0.08 & 2.85 & 2655 \\
7 & The Journal of Physical Chemistry B & 2000 & 5.61 & 0.04 & 44.32 & 2645
\end{tabular}




\begin{tabular}{lllllll}
8 & Advanced Materials & 1995 & 1.36 & 0.12 & 2.62 & 2571 \\
9 & Angewandte Chemie International Edition & 1996 & 1 & 0.13 & & 2392 \\
10 & Chemical Communications & 1999 & 1.11 & 0.11 & 0.98 & 2269 \\
\hline
\end{tabular}

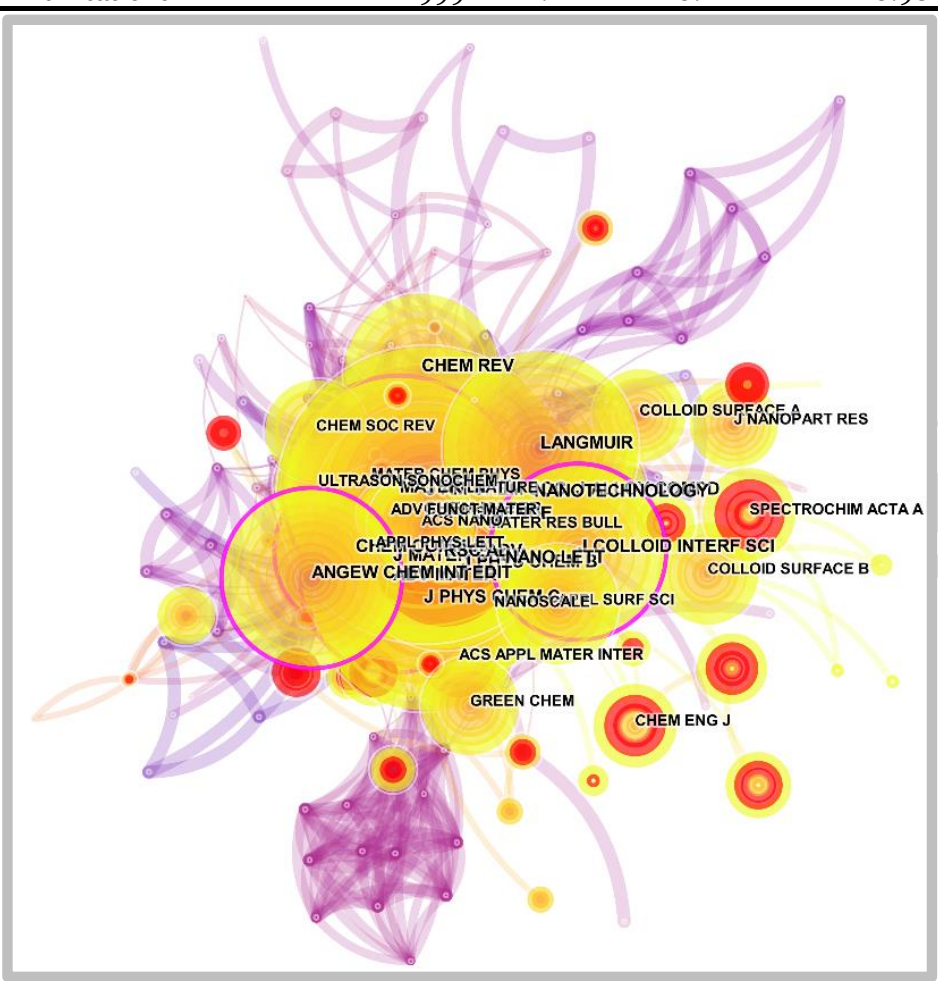

\section{Fig. 9.}

298 Outputs of CiteSpace regarding cited journals. The journals "American Chemical Society "and "Materials Letters" to which correspond 299 the largest nodes are the most cited journals.

Fig. 10.

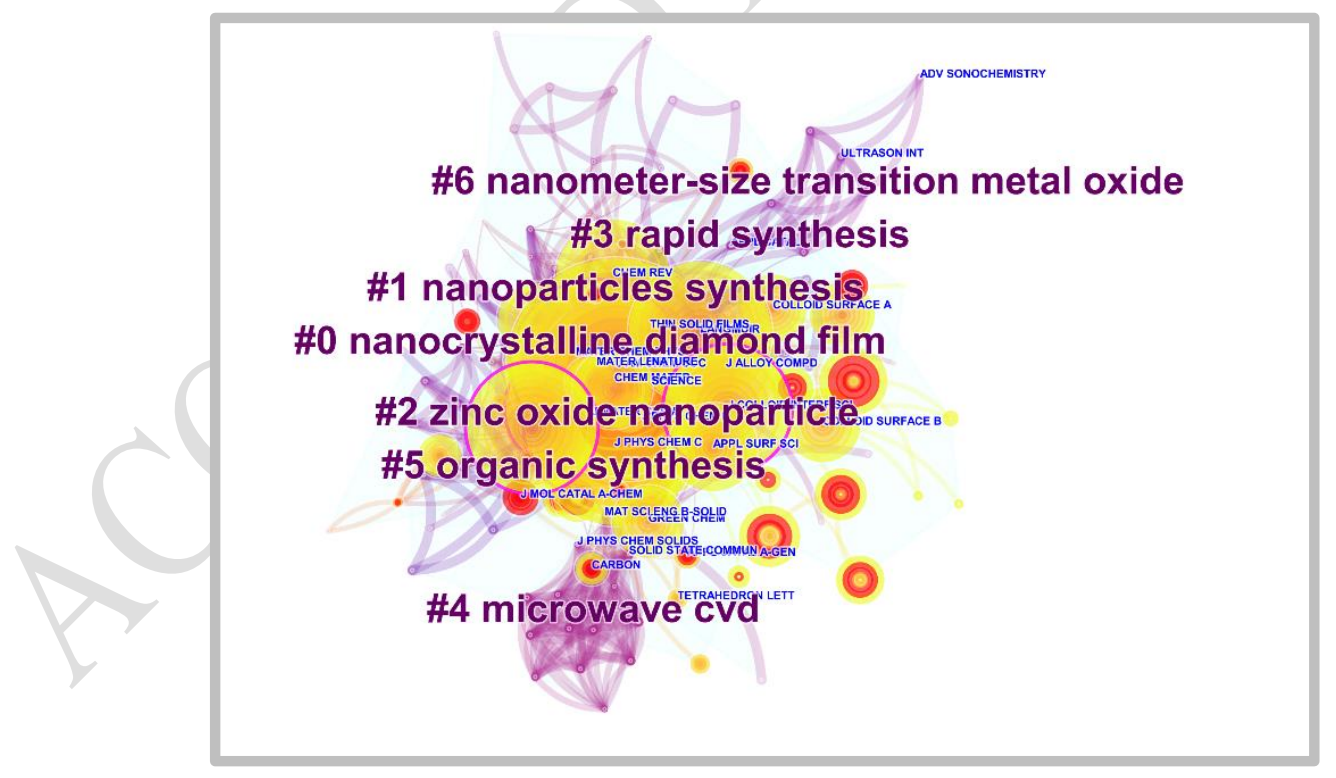

CiteSpace software outcomes on clusters of cited journals. In this figure, cluster\# o (nanocrystalline diamond film) contains the highest number of journals that have published documents analyzed in this study.

\section{6}

\subsection{Categories}



categories based on the number of documents are listed in Table 6.

Table 6.

\begin{tabular}{lll}
\hline Rating & Categories & Number of documents \\
\hline 1 & Materials Science, Multidisciplinary & 2776 \\
2 & Chemistry, Multidisciplinary & 2371 \\
3 & Chemistry, Physical & 1308 \\
4 & Physics, Applied & 1302 \\
5 & Nanoscience \& Nanotechnology & 1202 \\
6 & Physics, Condensed Matter & 680 \\
7 & Engineering, Chemical & 614 \\
8 & Chemistry, Inorganic \& Nuclear & 433 \\
9 & Acoustics & 328 \\
10 & Materials Science, Ceramics & 312 \\
\hline
\end{tabular}

Rating of documents categories based on documents number. As shown "Materials science, Multidisciplinary" is the category with highest number of documents.

\section{$313 \quad \mathbf{3 . 9}$ Cited articles}

314 The results achieved via WoS in terms of the top 10 highly cited articles during the period ranging from 3151991 to 2019 are presented in Table 7 and Fig. 11.

316 Table 7.

The more highly cited articles in the field under analysis. The article titled "Silver nanoparticles: Green synthesis and their antimicrobial activities" stands out as the most cited one [48].

\begin{tabular}{|c|c|c|c|}
\hline Rank & Title of the article & $\begin{array}{l}\text { Total } \\
\text { Citations }\end{array}$ & Ref. \\
\hline 1 & Silver nanoparticles: Green synthesis and their antimicrobial activities & 1996 & {$[48]$} \\
\hline 2 & A Green Approach to the Synthesis of Graphene Nanosheets & 1614 & [49] \\
\hline 3 & Completely green synthesis and stabilization of metal nanoparticles & 1413 & [50] \\
\hline 4 & Green synthesis of metal nanoparticles using plants & 1008 & {$[51]$} \\
\hline 5 & $\begin{array}{l}\text { Reducing Sugar: New Functional Molecules for the Green Synthesis of Graphene } \\
\text { Nanosheets }\end{array}$ & 982 & {$[52]$} \\
\hline 6 & Applications of Ultrasound to the Synthesis of Nanostructured Materials & 968 & {$[53]$} \\
\hline 7 & $\begin{array}{l}\text { Microwave synthesis of fluorescent carbon } \\
\text { electrochemiluminescence properties }\end{array}$ & 778 & {$[54]$} \\
\hline 8 & Microwave chemistry for inorganic nanomaterials synthesis & 660 & {$[55]$} \\
\hline 9 & $\begin{array}{l}\text { Photochemical green synthesis of calcium-alginate-stabilized } \mathrm{Ag} \text { and } \mathrm{Au} \\
\text { nanoparticles and their catalytic application to 4-nitrophenol reduction }\end{array}$ & 641 & [56] \\
\hline 10 & $\begin{array}{l}\text { Economical, green synthesis of fluorescent carbon nanoparticles and their use as } \\
\text { probes for sensitive and selective detection of mercury(II) ions }\end{array}$ & 615 & [57] \\
\hline
\end{tabular}




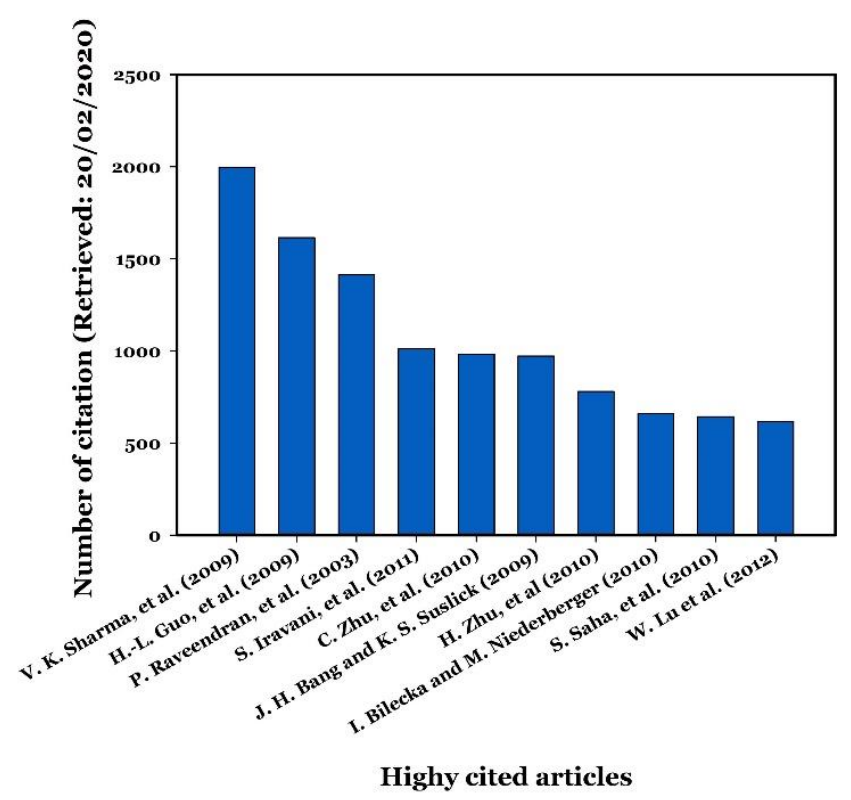

\section{Fig. 11.}

Graphical presentation of WoS results in terms of the top 10 highly cited articles during the period ranging from 1991 to 2019.

\section{Discussion}

In the present section an historical background covering the synthesis of nanomaterials will be firstly provided in order to frame a comprehensive definition of the term "green synthesis" which evolution over the years will be subsequently traced and discussed.

Synthesis of nanomaterials is thought to have been introduced by Michael Faraday (1850s) while preparing activated gold nanoparticles [58]-[61]. Faraday could demonstrate the differences in optical properties between bulk and nano-sized colloidal gold particles [59]. At that time Faraday was not able to prove by direct methods the nanometric size of the particles he had synthesized. It was only a century later that an innovative technique (electron microscopy) allowed disclosing the nanometric size of Faraday colloidal gold which average particle size ranged from 3 to $30 \mathrm{~nm}$ [6o]. The concept of "nanometer" was introduced in 1925 by Richard Zsigmondy which research in colloids awarded him a Nobel Prize in Chemistry in 1925. The modern nanotechnology, however, was founded later in 1959 by Feynman with his famous words: "there is plenty of room at the bottom" [62]. Later, in the 1970s, Norio Taniguchi used the word "nanotechnology" to describe semiconductors processing with a nanometer-scale precision level. These were precursor milestones of Nanotechnology which flourishing period took place in the 1980s. Kroto, Smalley, and Curl in the 1980s discovered the fullerenes and Eric Drexler wrote the book entitled "Engines of Creation: The Coming Era of Nanotechnology" published in 1986 [62]. The last decade of the twentieth century, driven by a growing awareness of the need of pollution prevention, seeded the first steps in the "green synthesis" of NMs. The evolution of NMs green synthesis until the present days is mapped and analyzed in the discussion that follows, and its important milestones presented in table 8 and figure 12.

Table. 8. Milestones on the evolution of nanomaterials green synthesis over the period 1991-2019. 


\begin{tabular}{|c|c|c|c|}
\hline $\begin{array}{l}\text { Time } \\
\text { Period } \\
\end{array}$ & Remarks & $\begin{array}{l}\text { Number of } \\
\text { publications }\end{array}$ & $\begin{array}{l}\text { Leading } \\
\text { Country a. }\end{array}$ \\
\hline 1991-2000 & - First document published in WoS on NMs green synthesis. & 54 & USA \\
\hline 2001-2005 & - Introduction of the "Green Synthesis" term to the scientific community & 293 & China \\
\hline 2006-2010 & $\begin{array}{l}\text { - Remarkable advances in NMs green synthesis methods mostly due to } \\
\text { green methods such as biosynthesis } \\
\text { - Manipulation of NMs green synthesis conditions to improve the } \\
\text { properties of NMs }\end{array}$ & 1062 & China \\
\hline 2011-2014 & $\begin{array}{l}\text { - Promoting NMs synthesized by green methodologies for various } \\
\text { applications such as environmental clean-up, drug delivery, and energy } \\
\text { - Studies on the mechanisms of green synthesis methods. }\end{array}$ & 2238 & China \\
\hline 2015-2019 & $\begin{array}{l}\text { - Promoting the biosynthesis of NMs } \\
\text { - Green synthesis of NMs in compliance with environmental protection } \\
\text { agency (EPA) green chemistry's } 12 \text { principles. }\end{array}$ & 5114 & 1 \\
\hline
\end{tabular}

\section{4}

a. The countries with the highest number of Publication in the period under study.

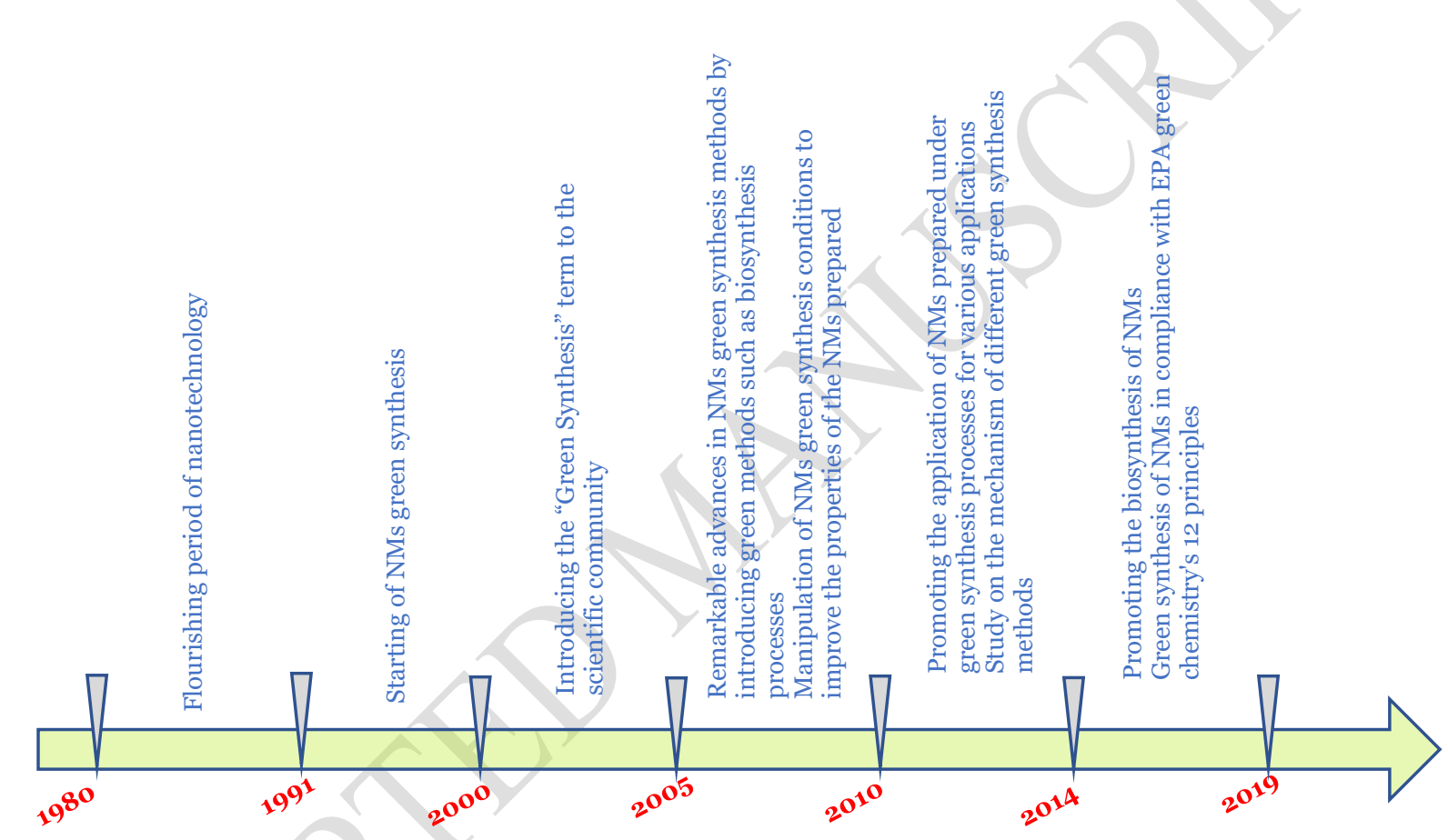

$346 \quad$ Fig. 12.

347 Milestones in the progress on green synthesis of NMs during the period 1991-2019.

The first attempts on green synthesis of NMs go back to 1991-2000 when ultrasonic irradiation (UI) was introduced as a green production technique for the synthesis of NMs, being the synthesis of $\mathrm{Si}_{3} \mathrm{~N}_{4} / \mathrm{SiC}$ ceramic nanocomposite by Gonsalves, K.E. et al (1991) one of the first study reporting on material synthesis assisted by UI [63]. In this decade 54 documents were published (Fig. 2) on green synthesis of NMs, most of them relying on UI. However, the number of publications in this period is relatively low, indicating that the scientific knowledge at that time was still at an infancy stage. UI was even not considered as a green production method but rather a tool to prepare NMs with desired properties. Microwave-assisted methods underwent a similar approach in this period of time. For instance, Yu et al (1998) fabricated polymerstabilized platinum colloids (with an average diameter of 2-4 $\mathrm{nm}$ ) using a household microwave oven as a heating device. They found that microwaves could heat a uniformly material in a glass or plastic reactor. 
Indeed, microwave irradiation favors homogeneous nucleation while allowing the reaction medium to heat helps to reduce the crystallization time as compared to other conventional heating methods. In this initial time period, the USA, with 22 published documents, was the country leading the publications in the field. One important reason accounting for this leadership was the development of the idea of "green chemistry" in response to the Pollution Prevention Act (1990), which fostered the Environmental Protection Agency (EPA) to design actions aimed at the reduction of environmental pollution. In the early 1990s, EPA and the National Science Foundation (NSF) in the USA started to fund research projects on the green chemistry of nanomaterials [65]. Also, green chemistry has been initially discussed in Chinese journals in 1994. In 1996 "Green Chemistry and Technology Symposium" was organized by the Academy and Science Department of China [X]. Among the publications in the same period, the work published by Kumar et al (2000) is worthy of mention for its higher number of citations (more than 460). These authors synthesized metallic oxide nanomaterials from metal acetates precursors using UI and discussed the mechanisms involved in their synthesis, which probably explained such a high citation. Among the more active authors, Gedanken. A. et al from Israel with 12 and 28 publications during the periods 1991-2000 and 2001-2005, respectively, owned the highest number of publications in this field [67]. Their work was mainly focused on the synthesis of nanomaterials such as iron nitride using UI. In 2000, Gedanken. A. et al authored 7 papers on UI synthesis of nanomaterials which were highly cited ( $>1300$ citations), where they discussed the different mechanisms involved in the UI process, supported by the effects of different experimental conditions on the properties of synthesized NMs (e.g., morphology, size, surface area, band gap, magnetic and optical). They also combined the UI based synthesis with other synthesis methods such as those based on heat treatment [66], [68]-[73]. Among the keywords with higher frequency over 1991-2000 period, the following are here highlighted: nanoparticle, sonochemical synthesis, size, powder; these keywords evidence that particle size reduction at the nanometer scale was at the time an effective concern among the scientific community [68], [74]. Sonochemical based methods offer a number of advantages such as being cost-effective, the possibility to be combined with other synthesis methods, being eco-friendly and ability to grant the NMs particles with the desired properties (i.e., size, crystallinity, surface area, morphology, etc.) [75]. Concluding, during the last decade of the twentieth century, prompted by the nascent idea of "green chemistry" or by UI- and Microwave-assisted methodologies, the research in the synthesis and control of NMs properties was significantly advanced. However, it is worthy remarking that the usefulness of these achievements for real applications of NMs was not addressed so far. The concept of "green synthesis" was consolidated in the period of 2001-2005. This term was used for the first time by Peng. X and Peng. Z. A. (2001) in their one-pot synthesis of cadmium chalcogenides using less toxic and cheaper reagents (i.e. cadmium oxide instead of dimethylcadmium as cadmium source) at room temperature. Later on, in 2003 this term was utilized by other researchers when reporting the synthesis of nanomaterials [77], [78], [Y]. This is the case of Raveendran. P. et al (2003) who reported the green synthesis of nanometals (like silver) relying on environmental friendly and renewable compounds such as water (solvent), sugar ( $\beta$-D-glucose, reducing agent), and starch (protecting agent), raising more than 1413 citations so far. EPA introduced "Green chemistry" as being the design of chemical products and processes 
that reduce or eliminate the use or generation of hazardous substances. Green chemistry may be applied across the life cycle of a product, including its design, manufacture, use, and ultimate disposal. Green chemistry is also known as "sustainable chemistry"[79]. The release of around 300 scientific publications highlights the progress of the green synthesis of NMs in that period of time (2001 -2005). Gedanken. A. from Israel with 28 documents had the highest number of publications in this field among the authors and the contributing countries. This encouraged the increase of Chinese research activities in the field of green chemistry at the service of NMs synthesis, which pushed the Chinese government to fund a number of projects. The resulting research momentum also led to the establishment of various Chinese scientific institutions and associated laboratories in this field [8o]. In line with this surge of research activities during the first half-decade of the $21^{\text {st }}$ century, it may be observed that keywords like nanoparticle, growth, nanowire, irradiation, nanotube, powder, nanocrystal, size, film, and nanostructure reached their highest citation during this period (Fig. 7). There are other keywords like shape and morphology, nanomaterials properties and methods of synthesis that have also deserved some attention during that period [81]-[84]. More recently, Matus. K.A.J et al, (2012) investigated the existing policies and improvement opportunities for green chemistry and engineering in China in order to identify the challenges that China has to overcome

412 for sustainable development. The activities mentioned in this section are probably the main reasons 413 accounting for China's leading position among countries with the highest numbers of publications in this 414 field (Fig. 4), mainly articles (Fig. 3). Briefly, the research carried out during this time period can be 415 considered a precursor to the sustainable development of NMs although in a restricted sense; since its focus was essentially on the transition to less toxic and environmentally friendly precursors, not taking into account any other sustainability pillars such as economic criteria.

The period 2006 to 2010 can be considered a birth period of new synthesis processes of NMs such as biosynthesis methods. In addition, the manipulation of the synthesis conditions aiming to improve the properties of NMs was also particularly pursued in this period. Hence more than 1000 documents were published, and the rate of publication increased notably in this field. China maintained its leading position, as a country, while among the authors Varma et al. from the USA owned the highest number of publications in this period, thanks to their investment on the control of nanomaterials morphology, especially during 2006 and 2007 [86]-[88]. They explored the preparation of NMs using plants as precursors [89], [90]. For instance, they synthesized Ag and Pd nanoparticles (20-60 nm) from powders of dehydrated coffee and tea leafs at room temperature without the need of surfactants or capping agents often reported [91]. The authors found that polyphenol existing in the used natural precursors can act as a suitable reducing and capping agent for the sake of controlling the size of synthesized NMs in the range of 20-60 nm [91]. Among the documents published in this period, the paper by Sharma, Yngard, and Lin (2009) received the largest number of citations, above 1996. In this study, the authors reviewed the green synthesis process of Ag nanoparticles and the mechanisms underlying their antibacterial activity. Another highly cited paper in the same period belongs to Guo et al. (2009) who introduced a green method for the synthesis of graphene nanosheets via electrochemical reduction of exfoliated graphite oxide. This article has been cited more than 1614 times until 2018. The analysis of the keywords in this period (Figures 6 and 7) reveals the words 
nanoparticle, growth, nanocrystal, nanostructure, nanowire and nanorod as the most frequently cited. This results indicates that, in this period, scientists were focused on the manipulation of synthesis conditions in order to tailor the properties of the synthesized nanomaterials [53]-[55], [92]-[97]. Despite the significant progress achieved in this period regarding the control and improvement of NMs properties, no comprehensive study encompassing all the green synthesis principles was published.

The following years, from 2011 to 2014, brought rapid developments to the production and application of NMs within the framework of green synthesis principles. Some oxides like $\mathrm{ZnO}$ or $\mathrm{TiO} 2$ are here cited as examples of antibacterial, wound healing and antioxidant [98] or photocatalyst and antiparasitic applications [99]. A particular focus was also paid to the understanding of the mechanisms involved in green synthesis processes. More than 2200 documents were published during this period, thus demonstrating the great interest raised by this subject among the scientific community. China kept its leadership in the number of publications and, among the authors, M. Salavati-Niasari from Iran, authored the largest number of publications in this field (figures 5, 8 and 9). UI and microwave approaches were deeply explored by several authors, especially by Salavati-Niasari, regarding the preparation of various types of nanoparticles with specific properties to be used for different purposes such as environmental clean-up and energy applications [100], [101] (see figures 9 and 10). Among the published documents, the review paper published by Iravani (2011b) was the most cited work (citations >1000) (Fig. 11). This paper reviewed the synthesis methodologies of metallic nanoparticles using plants as precursors (such as Aloe

453 Vera, Black tea, Eucalyptus, Parthenium hysterophorus, etc.). Another highly cited work in this period, with 454 more than 600 citations belongs to Lu et al. (2012). This paper reports the synthesis by a hydrothermal method of fluorescent carbon nanoparticles to be applied in sensing systems targeted to detect $\mathrm{Hg}^{2+}$ in aqueous media. The following keywords can be highlighted in this period: nanoparticle, nanocrystal, nanostructure, silver nanoparticle, gold nanoparticle, nanocomposite, green synthesis, growth, particle, optical property, nanorod, film, reduction, microwave, composite, size, nanowire, catalyst, biosynthesis, metal nanoparticle, oxide, fabrication, and thin film. This finding demonstrates clearly that the number of scientific terms used in publications on green synthesis of NMs kept increasing. However, key aspects regarding economic considerations were not discussed in these papers, hence indicating that one of the principles of green chemistry (Table 9) was not yet appropriately addressed, even in this more recent period [103]-[108]. Concluding, despite being a significant milestone, the application of NMs engineered according to the green synthesis principles has remained confined to the lab-scale in many important fields, not spilling over into real applications. In fact, the rate of knowledge transfer from the lab to the real applications underwent a significant increase in some areas like biomedical engineering, but no evidence of commercialization has been observed in other important applications such as the treatment of polluted waters and wastewaters.

The last stage of the scientific progress in this field covers the years from 2015 to 2019, where biosynthesis of nanomaterials has drawn increasing attention from the scientific community. It can be 471 inferred that researchers were now more attentive to the 12 main principles of green chemistry defined by 472 EPA (Table 9). In this period about 5114 documents were published and the number of publications still 
473 kept increasing continuously. Despite the previous stages, India surpassed China and owned the highest 474 number of publications. This is not surprising as India benefits from a strong material and chemistry 475 industrial basis. India is currently considered a leading country in many industries such as pesticides, 476 pharmaceutical and petrochemical with a number of environmental adverse effects such as hazardous waste 477 and wastewater, and harmful gas emissions which are at the origin of different environmental impacts such 478 as severe environmental resources pollution (groundwaters, for instance) and health problems such as 479 cancer, reproductive damage, breathing problems, allergy, liver and kidney problems [109], [110]. In this 480 regard, green chemistry principles may guide the chemical industries of developing countries like India to 481 reach a sustainable development [111]. Indian universities have also tried to promote their activities on the 482 green synthesis of NMs. The University of Delhi, for instance, has recently launched the Green Chemistry 483 Institute with a focus on activities supporting green chemistry innovation [112]. In 2014 the first national 484 chemical policy was approved in India [113], which has been raising an increasing national sensitiveness to 485 the benefits of green synthesis. Among the authors, Masoud Salavati-Niasari continued being a top author 486 in terms of the number of published documents with 59 papers published. Regarding highly cited 487 documents, the review paper by Ahmed et al. (2016) [114] on the synthesis of Ag mediated by plants extract 488 for antibacterial activities received more than 597 citations. In this review paper, biosynthesis and 489 conventional methods for the synthesis of Ag nanoparticles are compared while the advantages of this green 490 methodology in terms of economic, environment-friendly, and efficiency aspects are addressed as well. 491 Among the keywords introduced in literature during this period, nanoparticle, silver nanoparticle, green 492 synthesis, and biosynthesis were the most cited ones. Although green synthesis terminology has reached a 493 certain maturity in this period (2015-2019), it is here considered that one step forward can be taken by 494 introducing sustainability considerations towards "sustainable synthesis" of NMs. Sustainability is a 495 concept that integrates social and economic aspects in addition to the environmental conditions demanded 496 by green synthesis. Sustainability aims to save natural resources while promoting materials production 497 techniques assisted by economic considerations and raising a high degree of social acceptability. Some 498 literature reports have already introduced economic considerations criteria in the selection of a synthesis 499 process, [115]-[118]. However, highly

501 Table 9. The 12 main principles of green chemistry, adopted from EPA [79].

\begin{tabular}{ll}
\hline Row & Green chemistry principles \\
\hline 1 & Prevent waste \\
2 & Maximize atom economy \\
3 & Design less hazardous chemical syntheses \\
4 & Design safer chemicals and products \\
5 & Use safer solvents and reaction conditions \\
6 & Increase energy efficiency \\
7 & Use renewable feedstocks \\
8 & Avoid chemical derivatives \\
9 & Use catalysts, not stoichiometric reagents \\
10 & Design chemicals and products to degrade after use \\
11 & Analyze in real time to prevent pollution \\
12 & Minimize the potential for accidents \\
\hline
\end{tabular}


important aspects such as investment and equipment maintenance costs have not been included [119], [120]. Furthermore, no report is currently found on the social impacts of the methods capable of large scale synthesis of NMs, such as social acceptance and ability to create new job opportunities [119], [121]. As a final comment, we may refer that some evidences of real applications of NMS were recorded in this last period. For instance, the first commercial nano-reactors were introduced for the treatment of polluted waters and wastewaters [15]. However, despite the wide range of applications for nanotechnology based products, the number of NMs transferred from lab to real applications is still limited. The main reasons accounting for this gap include the lack of information on economic issues as well as social acceptability of the NMs produced and also the deficient knowledge about the potential of methods for scaling-up. To overcome these still existing barriers, future studies on the synthesis of NMs are highly encouraged to address the sustainability criteria defined very recently in the scientific literature including its technical, environmental, economic and social pillars [122]. It is envisaged that this strategy will aid the involved parties to select the most sustainable methods for NMs production in order to push further the commercialization of the methodologies already developed while attracting future investments on the research of novel methodologies, more compliant with sustainability principles.

\section{Final remarks and future research directions}

So far, many efforts have been directed for the synthesis of various types of NMs for a number of applications, from biomedical to water and wastewater treatment applications. The present scientometric study has demonstrated that the NMs green synthesis reported in the literature cannot satisfy the sustainable development goals which require a certain product to be of high quality (in this case efficient), environmentally friendly, economical and socially acceptable. The main emphasis has been given to the technical conditions required to NMs green synthesis and to the intended application for the developed NMs, being very scarce the reports encompassing the economic issues underlying the NMs production process. Furthermore, both the environmental impacts of the developed synthesis methodologies and their social acceptability have not been sufficiently addressed in the literature. These are limitations that may hamper the widespread utilization of the developed NMs in various applications (especially for state-ofthe-art) where there is an urgent need for efficient, cheap, safe, and socially acceptable materials and technologies. Hence, the following research directions can be here suggested for future studies:

a) To identify the main technical, environmental, economic, and social criteria and their relevant subcriteria that may affect the sustainability of NMs synthesis processes.

b) To adopt efficient synthesis methodologies in order to prioritize the identified sustainability criteria and sub-criteria that ensure the involvement of the scientific community in this process. Multi-criteria decision making processes such as fuzzy-Delphi methodology can be suggested as a useful tool for this purpose [15].

c) To apply cost-effective methodologies such as Taguchi experimental design which can considerably reduce the investments required for the optimization of the properties of the 
nanomaterials for the desired applications, especially for the most efficient methodologies identified in item (b).

d) To attract investments for pilot and real scale application of NMs taking into account all the sustainability criteria discussed in this study in order to facilitate their commercialization.

In this regard, future studies addressing sustainability criteria in the synthesis of NMs in order to

544 here envisaged that such studies may also trigger a new surge of publications. Furthermore, it is anticipated 545 that merging green chemistry and economic principles may also provide a basis for addressing the synthesis 546 of nanomaterials according to frugal innovation, with significant and positive impact in developing 547 countries.

\section{Conclusion and perspective}

A map of the scientific progress on green synthesis of NMs has been here presented. Information about the number of documents published annually, document types, countries and authors' contributions, evolution trends of scientific keywords, the most cited authors and journals, scientific categories appearing in this field over time, and the most cited articles have been collected and utilized to critically evaluate the 8761 documents extracted from WoS database using a proper set of keywords. The analysis of results evidences a relative maturity of the scientific progress in the field of green synthesis of NMs. Till now the term "green synthesis" has meant to exclude synthesis processes with adverse effects on the environment such as environmental pollution by produced wastes. However, there are numerous technical, environmental, economic and social considerations that need to be taken into consideration to satisfy the current and future needs of efficient, cost-effective and environmentally-friendly methods for the production of NMs. To address this gap, it is suggested in this study to refocus on "sustainable synthesis" by including all the technical, social and economic considerations besides environmental drawbacks.

\section{Acknowledgments}

Thanks are due, for the financial support to CESAM (UID/AMB/50017), and to CICECO-Aveiro

564 and the co-funding by the FEDER, within the PT2020 Partnership Agreement and Compete 2020. Thanks, are also due to FCT for the doctoral scholarship No. SFRH/BD/140873/2018 for the first author.

\section{References:}

567 [1] C. K. Choo et al., "Synthesis and Characterization of NiO Nano-Spheres by Templating on Chitosan as a Green Precursor,” J. Am. Ceram. Soc., vol. 99, pp. 3874-3882, 2016.

570 [3] M. I. Skiba, V. I. Vorobyova, A. Pivovarov, and N. P. Makarshenko, "Green Synthesis of Silver Nanoparticles in the Presence of Polysaccharide : Optimization and Characterization," $J$. Nanomater., vol. 2020, pp. 1-10, 2020.

[4] K. Rajendaran, R. Muthuramalingam, and S. Ayyadurai, “Green synthesis of Ag-Mo/CuO 
nanoparticles using Azadirachta indica leaf extracts to study its solar photocatalytic and antimicrobial activities," Mater. Sci. Semicond. Process., vol. 91, no. November 2018, pp. 230238, 2019.

577 [5] J. Saha, A. Begum, A. Mukherjee, and S. Kumar, "A novel green synthesis of silver nanoparticles and their catalytic action in reduction of Methylene Blue dye,” Sustain. Environ. Res., vol. 27, no. 5, pp. 245-250, 2017.

[6] R. C. Fierascu, A. Ortan, S. M. Avramescu, and I. Fierascu, "Phyto-Nanocatalysts: Green Synthesis, Characterization, and Applications," Molecules, pp. 1-35, 2019.

[7] E. Mosaddegh, "Ultrasonic-assisted preparation of nano eggshell powder: A novel catalyst in green and high efficient synthesis of 2-aminochromenes," Ultrason. Sonochem., vol. 20, no. 6, pp. 14361441, Nov. 2013.

[8] S. Sadjadi, M. Malmir, and M. M. Heravi, "A green approach to the synthesis of Ag doped nano magnetic gamma-Fe2O3@SiO2-CD core-shell hollow spheres as an efficient and heterogeneous catalyst for ultrasonic-assisted $\mathrm{A}(3)$ and $\mathrm{KA}(2)$ coupling reactions," RSC Adv., vol. 7, no. 58, pp. 36807-36818, 2017.

[9] Y. Zheng et al., "Sonochemistry-assisted microwave synthesis of nano-sized lanthanide activated phosphors with luminescence and different microstructures," Mater. Lett., vol. 113, pp. 90-92, 2013.

[11] M. E. Mahmoud, A. E. H. Abdou, and G. M. Nabil, "Facile microwave-assisted fabrication of nano-

[10] M. E. Mahmoud and G. M. Nabil, "Nano zirconium silicate coated manganese dioxide nanoparticles: Microwave-assisted synthesis, process optimization, adsorption isotherm, kinetic study and thermodynamic parameters for removal of 4-nitrophenol," J. Mol. Liq., vol. 240, pp. 280-290, 2017.

[12] Z. Yang et al., "Microwave dielectric properties of B and N co-doped SiC nanopowders prepared by zirconium silicate-functionalized-3-aminopropyltrimethoxysilane as a novel adsorbent for superior removal of divalent ions," J. Ind. Eng. Chem., vol. 32, pp. 365-372, 2015. combustion synthesis," J. Alloys Compd., vol. 777, pp. 1039-1043, 2019.

[13] E. Burgaz, A. Erciyes, M. Andac, and O. Andac, "Synthesis and characterization of nano-sized metal organic framework-5 (MOF-5) by using consecutive combination of ultrasound and microwave irradiation methods," Inorganica Chim. Acta, vol. 485, pp. 118-124, Jan. 2019.

[14] Y.-H. H. Hwang, D.-G. G. Kim, and H.-S. S. Shin, "Effects of synthesis conditions on the characteristics and reactivity of nano scale zero valent iron," Appl. Catal. B Environ., vol. 105, no. 1-2, pp. 144-150, Jun. 2011.

[15] M. Kamali, K. M. Persson, M. E. Costa, and I. Capela, "Sustainability criteria for assessing nanotechnology applicability in industrialwastewater treatment: Current status and future outlook," Environ. Int., vol. 125, no. January, pp. 261-276, 2019.

[16] J. Singh, T. Dutta, K. H. Kim, M. Rawat, P. Samddar, and P. Kumar, “' Green ' synthesis of metals and their oxide nanoparticles : applications for environmental remediation," $J$. 
Nanobiotechnology, pp. 1-24, 2018.

613 [17] A. I. Journal, M. Rafique, I. Sadaf, M. S. Rafique, and M. B. Tahir, "A review on green synthesis of silver nanoparticles and their applications," Artif. Cells, Nanomedicine, Biotechnol., vol. o, no. o, pp. 1272-1291, 2017.

[18] M. Kamali, "Guest Editorial: An Opinion on Multi-Criteria Decision-Making Analysis for Sustainability-Based Spatial Planning Practices . Time to Improve ?,” J. Settlements Spat. Plan., vol. In press, pp. 1-3, 2020.

[19] E. de Wit-de Vries, W. A. Dolfsma, H. J. van der Windt, and M. P. Gerkema, "Knowledge transfer in university-industry research partnerships: a review," J. Technol. Transf., vol. 44, no. 4, pp. 1236-1255, 2019.

[20] P. D’Este and M. Perkmann, "Why do academics engage with industry? The entrepreneurial university and individual motivations," J. Technol. Transf., vol. 36, no. 3, pp. 316-339, 2011.

[21] O. Konur, "The Evaluation of the Global Research on the Education: A Scientometric Approach," Procedia - Soc. Behav. Sci., vol. 47, pp. 1363-1367, 2012.

[22] T. Ahmad and M. J. Thaheem, "Developing a residential building-related social sustainability assessment framework and its implications for BIM,” Sustain. Cities Soc., vol. 28, pp. 1-15, 2017.

[23] T. O. Olawumi and D. W. M. Chan, "A scientometric review of global research on sustainability and sustainable development," J. Clean. Prod., vol. 183, pp. 231-250, 2018.

[24] S. Jiang, K. F. L. Hagesteijn, J. Ni, and B. P. Ladewig, "A scientometric study of the research on ion

[26] C. Chen, Z. Hu, S. Liu, and H. Tseng, "Emerging trends in regenerative medicine: a scientometric analysis in CiteSpace," Expert Opin. Biol. Ther., vol. 12, no. 5, pp. 593-608, 2012.

[27] W. Ouyang et al., "Heavy metal loss from agricultural watershed to aquatic system: A scientometrics review," Sci. Total Environ., vol. 637-638, pp. 208-220, 2018.

[28] M. Davarazar et al., "Underground carbon dioxide sequestration for climate change mitigation - A scientometric study," J. CO2 Util., vol. 33, no. May, pp. 179-188, 2019.

[29] Z. Cai et al., "Large-scale and fast synthesis of nano-hydroxyapatite powder by a microwavehydrothermal method," RSC Adv., vol. 9, no. 24, pp. 13623-13630, 2019.

644 [31] C. Chen, “CiteSpace Quick Guide 1.2,” Drexel University, 2005.

645 [32] C. Chen, "The CiteSpace Manual version 1.01," in College of Computing and Informatics, 2014, pp. $1-84$.

647 [33] L. C. Freeman, "A Set of Measures of Centrality Based on Betweenness," Sociometry, vol. 40, no. 1, $648 \quad$ pp. 35-41.

649 [34] S. K. R, K. Balakrishnan, and M. Jathavedan, "Betweenness Centrality in Some Classes of Graphs," 
Int. J. Comb., no. ii, 2014.

[35] J. O. N. Kleinberg, "Bursty and Hierarchical Structure in Streams," Data Min. Knowl. Discov., vol. 7, pp. 373-397, 2003.

[36] C. Chen et al., "The Structure and Dynamics of Co Citation Clusters : A Multiple Perspective CoCitation Analysis .," J. Am. Soc. Infor- mation Sci. Technol. Assoc. Inf. Sci. Technol. (ASIS T), vol. 61, no. 7, pp. 1386-1409, 2011.

[37] N. M. Lindner, C. B. Hawkins, J. Joy-gaba, and E. R. Tenney, "Cumulative and career-stage impact of social-personality psychology programs and their members," Personal. Soc. Psychol. Bull., no. 36, pp. 1283-1300, 2010.

[38] M. O’Brien, "Research impact guide: Citation counts," UNSW Sydney, 2019. .

[39] R. Leimu and J. Koricheva, "What determines the citation frequency of ecological papers?," Trends Ecol. Evol., vol. 20, no. 1, pp. 28-32, 2005.

[40] United States Environmental Protection Agency, "Bibliometrics Analysis for TSE Grant Publications," 2004.

664 [41] R. Cornish, "Cluster Analysis Hierarchical agglomerative methods," Analysis, pp. 1-5, 2007.

[42] R. Shrivastava and P. Mahajan, "Artificial Intelligence Research in India: A Scientometric Analysis," Sci. Technol. Libr., vol. 35, no. 2, pp. 136-151, 2016.

[43] H. N. Su and P. C. Lee, "Mapping knowledge structure by keyword co-occurrence: A first look at journal papers in Technology Foresight," Scientometrics, vol. 85, no. 1, pp. 65-79, 2010.

[44] A. Darko, A. P. C. Chan, X. Huo, and D.-G. Owusu-Manu, "A scientometric analysis and visualization of global green building research," Build. Environ., vol. 149, no. November 2018, pp. 501-511, 2019.

[45] X. Zhao, "A scientometric review of global BIM research: Analysis and visualization," Autom. Constr., vol. 8o, pp. 37-47, 2017.

[46] Y. Ding, "Scientific collaboration and endorsement: Network analysis of coauthorship and citation networks," J. Informetr., vol. 5, no. 1, pp. 187-203, 2011.

[47] M. R. Hosseini, I. Martek, E. K. Zavadskas, A. A. Aibinu, M. Arashpour, and N. Chileshe, "Critical evaluation of off-site construction research: A Scientometric analysis,” Autom. Constr., vol. 87, no. July 2017, pp. 235-247, 2018.

[48] V. K. Sharma, R. A. Yngard, and Y. Lin, "Silver nanoparticles: Green synthesis and their antimicrobial activities," Adv. Colloid Interface Sci., vol. 145, no. 1-2, pp. 83-96, 2009.

[49] H.-L. Guo, X.-F. Wang, Q.-Y. Qian, F.-B. Wang, and X.-H. Xia, “A Green Approach to the Synthesis of Graphene Nanosheets,” ACS Nano, vol. 3, no. 9, pp. 2653-2659, Sep. 2009.

[50] P. Raveendran, J. Fu, and S. L. Wallen, "Completely 'Green' Synthesis and Stabilization of Metal Nanoparticles,” J. Am. Chem. Soc., vol. 125, no. 46, pp. 13940-13941, Nov. 2003.

[51] S. Iravani, “Green synthesis of metal nanoparticles using plants," Green Chem., vol. 13, no. 10, pp. 2638-2650, 2011.

[52] C. Zhu, S. Guo, Y. Fang, and S. Dong, "Reducing Sugar: New Functional Molecules for the Green 
Synthesis of Graphene Nanosheets," ACS Nano, vol. 4, no. 4, pp. 2429-2437, Apr. 2010.

[53] B. Jin, H. Bang, K. S. Suslick, J. H. Bang, and K. S. Suslick, "Applications of Ultrasound to the Synthesis of Nanostructured Materials," Adv. Mater., vol. 22, pp. 1039-1059, 2010.

[54] H. Zhu, X. Wang, Y. Li, Z. Wang, F. Yang, and X. Yang, "Microwave synthesis of fluorescent carbon nanoparticles with electrochemiluminescence properties," Chem. Commun., no. 34, pp. 51185120, 2009.

[55] I. Bilecka and M. Niederberger, "Microwave chemistry for inorganic nanomaterials synthesis," Nanoscale, vol. 2, no. 8, pp. 1358-1374, 2010.

[56] S. Saha, A. Pal, S. Kundu, S. Basu, and T. Pal, "Photochemical green synthesis of calcium-alginatestabilized ag and au nanoparticles and their catalytic application to 4-nitrophenol reduction," Langmuir, vol. 26, no. 4, pp. 2885-2893, 2010.

[57] W. Lu et al., "Economical, green synthesis of fluorescent carbon nanoparticles and their use as probes for sensitive and selective detection of mercury(II) ions," Anal. Chem., vol. 84, no. 12, pp. 5351-5357, 2012.

[58] J. Jeevanandam, A. Barhoum, Y. S. Chan, A. Dufresne, and M. K. Danquah, "Review on nanoparticles and nanostructured materials: History, sources, toxicity and regulations," Beilstein J. Nanotechnol., vol. 9, no. 1, pp. 1050-1074, 2018.

[59] F. J. Heiligtag and M. Niederberger, "The fascinating world of nanoparticle research," Mater. Today, vol. 16, no. 7-8, pp. 262-271, 2013.

[6o] P. P. Edwards and J. M. Thomas, "Gold in a metallic divided state - From Faraday to present-day nanoscience," Angew. Chemie - Int. Ed., vol. 46, no. 29, pp. 5480-5486, 2007.

[61] R. D. Tweney, "Discovering discovery: How faraday found the first metallic colloid," Perspect. Sci., vol. 14, no. 1, pp. 97-121, 2006.

[62] J. E. Hulla, S. C. Sahu, and A. W. Hayes, "Nanotechnology: History and future," Hum. Exp. Toxicol., vol. 34, no. 12, pp. 1318-1321, 2015.

[63] K. E. Gonsalves, P. R. Strutt, and T. D. Xiao, "Synthesis of ceramic nanoparticles by the ultrasonic injection of an organosilazane precursor," Adv. Mater., vol. 3, pp. 202-204, Apr. 1991.

[64] W. Yu, W. Tu, and H. Liu, "Synthesis of Nanoscale Platinum Colloids by Microwave Dielectric Heating," Langmuir, vol. 15, no. 1, pp. 6-9, 1998.

[65] "History of Green Chemistry," Yale University, 2017. .

[66] R. V. Kumar, Y. Diamant, and A. Gedanken, "Sonochemical Synthesis and Characterization of Nanometer-Size Transition Metal Oxides from Metal Acetates," Chem. Mater., vol. 12, no. 8, pp. 2301-2305, Aug. 2000.

[67] R. Prozorov, J. Balogh, A. Gedanken, Y. Koltypin, X. Cao, and D. Kaptas, "Sonochemical synthesis of iron nitride nanoparticles,” J. Mater. Chem., vol. 7, no. 12, pp. 2453-2456, 1997.

[68] R. Vijayakumar, Y. Koltypin, I. Felner, and A. Gedanken, "Sonochemical synthesis and characterization of pure nanometer-sized Fe 3 O 4 particles," Mater. Sci. Eng., vol. A286, pp. 101105, 2000 . 
[69] A. Gedanken, Z. Lu, D. Aurbach, S. T. Aruna, and J. Zhu, "Sonochemical Synthesis of SnO 2 Nanoparticles and Their Preliminary Study as Li Insertion Electrodes,” Chem. Mater., vol. 12, no. 9, pp. 2557-2566, 1999.

[70] V. G. Pol, R. Reisfeld, and A. Gedanken, "Sonochemical synthesis and optical properties of europium oxide nanolayer coated on titania," Chem. Mater., vol. 14, no. 9, pp. 3920-3924, 2002.

[71] L. Qiu, V. G. Pol, Y. Wei, and A. Gedanken, "A two-step process for the synthesis of MoTe2 nanotubes: Combining a sonochemical technique with heat treatment," J. Mater. Chem., vol. 13, no. 12, pp. 2985-2988, 2003.

[72] Q. Li et al., "Sonochemical synthesis, structural and magnetic properties of air-stable Fe/Co alloy nanoparticles," New J. Chem., vol. 27, no. 8, p. 1194, 2003.

[73] L. Qiu, V. G. Pol, J. Calderon-Moreno, and A. Gedanken, "Synthesis of tin nanorods via a sonochemical method combined with a polyol process," Ultrason. Sonochem., vol. 12, no. 4, pp. 243-247, 2005.

[74] S. Mintova, S. Mo, and T. Bein, "Nanosized AlPO 4 -5 Molecular Sieves and Ultrathin Films Prepared by Microwave Synthesis,” Chem. Mater., no. 18, pp. 4030-4036, 1998.

[75] M. Kamali, M. Elisabete, V. Costa, G. Otero-irurueta, and I. Capela, "Ultrasonic irradiation as a green production route for coupling crystallinity and high speci fi c surface area in iron nanomaterials," J. Clean. Prod., vol. 211, pp. 185-197, 2019.

[76] X. Peng and Z. A. Peng, "science/technology concentrates," Chem. Eng. News, vol. 79, no. 2, p. 25, Jan. 2001.

[77] I. Mekis, D. V. Talapin, A. Kornowski, M. Haase, and H. Weller, “One-Pot Synthesis of Highly Luminescent CdSe/CdS Core-Shell Nanocrystals via Organometallic and 'Greener' Chemical Approaches ${ }^{\dagger}$, , J. Phys. Chem. B, vol. 107, no. 30, pp. 7454-7462, Jul. 2003.

[78] J. Fu and P. Raveendran, "226th National Meeting of the American-Chemical-Society," in "Green" synthesis of metal nanoparticles., 2003, p. U119.

[79] EPA, "Basics of Green Chemistry," United States Environmental Protection Agency. .

[8o] Z. Cui, E. S. Beach, and P. T. Anastas, “Green chemistry in China,” Pure Appl. Chem., vol. 83, no. 7, pp. 1379-1390, 2011.

[81] L. Yin, Y. Wang, G. Pang, Y. Koltypin, and A. Gedanken, "Sonochemical synthesis of cerium oxide nanoparticles - Effect of additives and quantum size effect," J. Colloid Interface Sci., vol. 246, no. 1, pp. 78-84, 2002.

[82] J. Geng, W. H. Hou, Y. N. Lv, J. J. Zhu, and H. Y. Chen, "One-dimensional BiPO4nanorods and two-dimensional $\mathrm{BiOCl}$ lamellae: Fast low-temperature sonochemical synthesis, characterization, and growth mechanism," Inorg. Chem., vol. 44, no. 23, pp. 8503-8509, 2005.

[83] J. M. Cao et al., "Microwave-assisted solid-state synthesis of hydroxyapatite nanorods at room temperature," J. Mater. Sci., vol. 40, no. 23, pp. 6311-6313, 2005.

[84] X. Sun and Y. Luo, "Size-controlled synthesis of dendrimer-protected gold nanoparticles by microwave radiation,” Mater. Lett., vol. 59, no. 29-30, pp. 4048-4050, 2005. 
[85] K. J. M. Matus, X. Xiao, and J. B. Zimmerman, "Green chemistry and green engineering in China: Drivers, policies and barriers to innovation,” J. Clean. Prod., vol. 32, pp. 193-203, 2012.

[86] M. N. Nadagouda, R. S. Varma, and C. S. Nanostructures, "A Greener Synthesis of Core ( Fe , Cu ) Des., vol. 7, no. 12, pp. 2582-2587, 2007.

[87] N. N. Mallikarjuna and R. S. Varma, "Microwave-assisted shape-controlled bulk synthesis of noble nanocrystals and their catalytic properties," Cryst. Growth Des., vol. 7, no. 4, pp. 686-690, 2007.

[88] M. N. Nadagouda and R. S. Varma, "Green and controlled synthesis of gold and platinum nanomaterials using vitamin B-2: density-assisted self-assembly of nanospheres, wires and rods," GREEN Chem., vol. 8, no. 6, pp. 516-518, 2006.

[89] M. N. Nadagouda, G. Hoag, J. Collins, and R. S. Varma, "Green synthesis of Au nanostructures at room temperature using biodegradable plant surfactants,” Cryst. Growth Des., vol. 9, no. 11, pp. 4979-4983, 2009.

[90] L. K. Braydich-Stolle, S. Kunzelman, S. M. Hussain, M. N. Nadagouda, R. S. Varma, and M. C. Moulton, "Synthesis, characterization and biocompatibility of 'green' synthesized silver nanoparticles using tea polyphenols,” Nanoscale, vol. 2, no. 5, p. 763, 2010.

[91] M. N. Nadagouda and R. S. Varma, "Green synthesis of silver and palladium nanoparticles at room temperature using coffee and tea extract," Green Chem., vol. 10, no. 8, pp. 859-862, 2008.

[92] G. A. Tompsett, W. C. Conner, and K. S. Yngvesson, "Microwave synthesis of nanoporous materials," ChemPhysChem, vol. 7, no. 2, pp. 296-319, 2006.

[93] Z. Q. Tian, S. P. Jiang, Y. M. Liang, and P. K. Shen, "Synthesis and characterization of platinum catalysts on multiwalled carbon nanotubes by intermittent microwave irradiation for fuel cell applications," J. Phys. Chem. B, vol. 110, no. 11, pp. 5343-5350, 2006.

[94] T. Muraliganth, K. R. Stroukoff, and A. Manthiram, "Microwave-solvothermal synthesis of nanostructured Li2MSiO 4/C (M = Mn and Fe) cathodes for lithium-ion batteries," Chem. Mater., vol. 22, no. 20, pp. 5754-5761, 2010.

[95] J. Yan et al., "Rapid microwave-assisted synthesis of graphene nanosheet/Co $3 \mathrm{O} 4$ composite for supercapacitors," Electrochim. Acta, vol. 55, no. 23, pp. 6973-6978, 2010.

[96] H. M. A. Hassan et al., "Microwave synthesis of graphene sheets supporting metal nanocrystals in aqueous and organic media," J. Mater. Chem., vol. 19, no. 23, pp. 3832-3837, 2009.

[97] A. V. Murugan, T. Muraliganth, and A. Manthiram, "Rapid, Facile Microwave-Solvothermal Synthesis of Graphene Nanosheets and Their Polyaniline Nanocomposites for Energy Strorage," Chem. Mater., vol. 21, no. 21, pp. 5004-5006, 2009.

[98] H. Agarwal, S. V. Kumar, and S. Rajeshkumar, "A review on green synthesis of zinc oxide nanoparticles - An eco-friendly approach,” Resour. Technol., vol. 3, pp. 406-413, 2017.

[99] M. Nadeem et al., "Green Chemistry Letters and Reviews The current trends in the green syntheses of titanium oxide nanoparticles and their applications," Green Chem., vol. 11, pp. 492$502,2018$. 
[100] F. Soofivand, F. Mohandes, and M. Salavati-Niasari, "Silver chromate and silver dichromate nanostructures: Sonochemical synthesis, characterization, and photocatalytic properties," Mater. Res. Bull., vol. 48, no. 6, pp. 2084-2094, 2013.

[101] S. M. Hosseinpour-Mashkani, F. Mohandes, M. Salavati-Niasari, and K. Venkateswara-Rao, "Microwave-assisted synthesis and photovoltaic measurements of CuInS 2 nanoparticles prepared by using metal-organic precursors,” Mater. Res. Bull., vol. 47, no. 11, pp. 3148-3159, 2012.

[102] S. Iravani, "GreenSynthesis of metal nanoparticles using plants," Acta Naturae, vol. 6, no. 20, pp. 35-44, 2011.

[103] C. F. Yan, J.-M. Yao, B. Sun, Z.-Y. Qin, and H.-Y. Yu, “One-pot green fabrication and antibacterial activity of thermally stable corn-like CNC/Ag nanocomposites,” J. Nanoparticle Res., vol. 16, no. 1, pp. 1-12, 2013.

[104] S. M. Badawy, "Green synthesis of dual-surface nanocomposite films using Tollen's method," Green Process. Synth., vol. 3, no. 6, pp. 463-469, 2014.

[105] I. Mtimet, L. Lecamp, N. Kebir, F. Burel, and T. Jouenne, "Green synthesis process of a polyurethane-silver nanocomposite having biocide surfaces,” Polym. J., vol. 44, no. 12, pp. 12301237, 2012.

[106] C. Coman et al., "Green synthesis of gold nanoparticles by Allium sativum extract and their assessment as SERS substrate," J. Nanoparticle Res., vol. 16, no. 1, 2014.

[107] H. Huang, H. Li, A. J. Wang, S. X. Zhong, K. M. Fang, and J. J. Feng, "Green synthesis of peptidetemplated fluorescent copper nanoclusters for temperature sensing and cellular imaging," Analyst, vol. 139, no. 24, pp. 6536-6541, 2014.

[108] H. K. Kim et al., "Earthworm extracts utilized in the green synthesis of gold nanoparticles capable of reinforcing the anticoagulant activities of heparin," Nanoscale Res. Lett., vol. 8, no. 1, pp. 1-7, 2013.

[109] N. Jain, P. Lakhani, and S. Gupta, "Impacts of Harmful Emissions near Chemical Based Industries in Gujarat on Impacts of Harmful Emissions Nearby Chemical based Industries in Gujarat on Environment with Major Focus on Human Health and Methods to Scale down its Impacts- A Review,” Int. J. Eng. Res. Technol., vol. Volume 5, no. Issue 12, pp. 1-9, 2016.

[110] A. Sharma, "Hazardous Effects of Petrochemical Industries: A Review," Recent Adv. Petrochemical Sci., vol. 3, no. 2, pp. 2-4, 2018.

[111] M. Kidwai, "Green chemistry in India," Pure Appl. Chem., vol. 73, no. 8, pp. 1261-1263, 2001.

[112] G. D. Yadav, "Green chemistry in India," Clean Techn Env. Policy, vol. 73, no. 8, pp. 219-223, 2006.

[113] D. of chemicals and Petrochemicals, "National Chemical Policy in the India," Dehli, 2014.

[114] S. Ahmed, M. Ahmad, B. L. Swami, and S. Ikram, "A review on plants extract mediated synthesis of silver nanoparticles for antimicrobial applications: A green expertise," J. Adv. Res., vol. 7, no. 1, pp. 17-28, 2016.

[115] J. L. Wang et al., "Recycling Nanowire Templates for Multiplex Templating Synthesis: A Green 
and Sustainable Strategy,” Chem. - A Eur. J., vol. 21, no. 13, pp. 4935-4939, 2015.

[116] F. N. Sayed and V. Polshettiwar, "Facile and Sustainable Synthesis of Shaped Iron Oxide Nanoparticles: Effect of Iron Precursor Salts on the Shapes of Iron Oxides," Sci. Rep., vol. 5, no. March, pp. 1-14, 2015.

844 [117] B. Kumar, K. Smita, L. Cumbal, and Y. Angulo, "Fabrication of silver nanoplates using Nephelium lappaceum (Rambutan) peel: A sustainable approach," J. Mol. Liq., vol. 211, pp. 476-480, 2015.

[118] H. Song, L. Hao, Y. Tian, X. Wan, L. Zhang, and Y. Lv, "Stable and water-dispersible graphene nanosheets: Sustainable preparation, functionalization, and high-performance adsorbents for $\mathrm{Pb}$ 2+," Chempluschem, vol. 77, no. 5, pp. 379-386, 2012.

849 [119] M. Cinelli, S. R. Coles, O. Sadik, B. Karn, and K. Kirwan, "A framework of criteria for the

850 sustainability assessment of nanoproducts,” J. Clean. Prod., vol. 126, pp. 277-287, 2016.

851 [120] J. Yuan, J. Yang, H. Ma, S. Su, Q. Chang, and S. Komarneni, “Green synthesis of nano-muscovite and niter from feldspar through accelerated geomimicking process," Appl. Clay Sci., vol. 165, no. April, pp. 71-76, 2018.

854 [121] M. Siegrist, M. E. Cousin, H. Kastenholz, and A. Wiek, "Public acceptance of nanotechnology foods and food packaging: The influence of affect and trust," Appetite, vol. 49, no. 2, pp. 459-466, 2007.

856 [122] M. Kamali, M. E. Costa, T. M. Aminabhavi, and I. Capela, "Sustainability of treatment technologies for industrial biowastes effluents," Chem. Eng. J., vol. 370, pp. 1511-1521, 2019. 


\section{Supplementary Information} synthesis nano* OR sustainable fabrication nano* OR sustainable preparation nano* OR sustainability synthesis nano* OR sustainability fabrication nano* OR sustainability preparation nano* OR ultrasonic synthesis nano* OR ultrasonic fabrication nano* OR ultrasonic preparation nano* OR ultrasound synthesis nano* OR ultrasound fabrication nano*OR ultrasound preparation nano* OR microwave synthesis nano* OR microwave fabrication nano* OR microwave preparation nano* OR sonochemistry synthesis nano* OR sonochemistry fabrication nano* OR sonochemistry preparation nano* OR sonochemical synthesis nano* OR sonochemical fabrication nano* OR sonochemical preparation nano* OR green synthesis nanomaterial*

OR green synthesis nanocomposite* OR green synthesis nanocatalyst* OR green preparation 874 nanomaterial* OR green preparation nanocomposite* OR green preparation nanocatalyst* OR green 875 fabrication nanomaterial* OR green fabrication nanocomposite* OR green fabrication nanocatalyst* OR sustainable synthesis nanomaterial* OR sustainable synthesis nanocomposite* OR sustainable synthesis

877 nanocatalyst* OR sustainable preparation nanomaterial* OR sustainable preparation nanocomposite* ${ }^{*}$ 878 sustainable preparation nanocatalyst* OR sustainable fabrication nanomaterial* OR sustainable fabrication nanocomposite* OR sustainable fabrication nanocatalyst* OR sustainability synthesis nanomaterial* OR sustainability synthesis nanocomposite* OR sustainability synthesis nanocatalyst* OR sustainability preparation nanomaterial* OR sustainability preparation nanocomposite* OR sustainability preparation nanocatalyst* OR sustainability fabrication nanomaterial* OR sustainability fabrication nanocomposite* OR sustainability fabrication nanocatalyst*)) OR (TI=(green* AND synthesis* AND

884 chemistry *) And TS=(nano*) $)$ OR $(\mathrm{TI}=($ green* AND preparation * AND chemistry *) And TS= $($ nano* $))$ OR 885 (TI=(green* AND fabrication * AND chemistry *) And TS=(nano*)) AND LANGUAGE: (English). 